\title{
El reto de pensar sobre los derechos fundamentales de los pueblos originarios
}

\author{
0 desafio de pensar sobre os direitos \\ fundamentais dos povos originários
}

\author{
Saulo Tarso Rodrigues \\ Núria Belloso Martín
}

\begin{abstract}
Resumen
Los derechos indígenas suponen un reto para el constitucionalismo latinoamericano en cuanto a su afectación a los derechos humanos, principalmente en cuanto a su relación con el derecho a la igualdad. Hay minorías, grupos diferenciados que, precisamente, para lograr que el principio de igualdad sea una realidad, deben hacerlo a partir de la diferencia y constituirse como "ciudadanos diferenciados". Las Constituciones que se enmarcan en el nuevo constitucionalismo latinoamericano, han acogido los derechos indígenas en un planteamiento que excede el modelo de Estado multiculturalista, orientándose hacia un Estado plurinacional. Ello permite que los derechos indígenas encuentren más fácilmente acomodo, sin el temor a que se les ofrezca una asimilación o tutelaje.
\end{abstract}

Palabras clave: Derechos fundamentales; indígenas; constitucionalismo latinoamericano.

\section{Resumo}

Os direitos indígenas pressupōem um desafio para o constitucionalismo latino-americano no que concerne às implicações dos direitos humanos, principalmente, com relação ao direito à igualdade. Há minorias, grupos diferenciados que, precisamente, para que o princípio da igualdade faça parte de sua realidade, devem realizá-lo a partir da diferença e constituir-se como "cidadãos diferenciados". As Constituiçōes, que se conformam ao novo constitucionalismo latino-americano, concebem os direitos indígenas de uma forma que excede o modelo do Estado multiculturalista, orientando-se a um Estado plurinacional. Isto permite que os direitos indígenas encontrem mais facilmente acomodação, sem o perigo da oferta por parte do Estado de uma assimilação ou tutela.

Palavras-chave: Direitos fundamentais; indígenas; constitucionalismo latino-americano. 


\section{Introducción ${ }^{1}$}

Contrasta el protagonismo que durante los siglos XVI y XVII tuvo todo lo relacionado con la conquista y colonización de las nuevas tierras descubiertas en el Nuevo Mundo, que incluso a través de la Escuela Española y de Francisco de Vitoria, sentaron las bases del moderno Derecho Internacional Público, con el escaso interés que durante los siglos sucesivos, hasta mediados del siglo $X X$, ha tenido la cuestión indígena. Valoraciones económicas, políticas, antropológicas, jurídicas, éticas (la denominada "ética colonial de la conquista de América") $)^{2}$ y tantas otras, tras una época de controversias y disputas encendidas, acabaron cayendo en el silencio en siglos posteriores. Ni el derecho internacional de los derechos humanos dedicó una especial atención a los derechos de las comunidades indias. Por el contrario, el Derecho internacional se fue consolidando progresivamente como un ordenamiento de los Estados.

Una de las grandes dificultades con que se ha tropezado el reconocimiento de la ciudadanía para los indios ha sido que la mayoría de las legislaciones del siglo XX han apuntado hacia el objetivo de la integración política y social.
Avanzada la década de los setenta es cuando comienza a manifestarse un cambio de perspectiva en el reconocimiento de los derechos de los pueblos indígenas. ${ }^{3}$ En esta línea, cabe destacar dos grandes hitos legislativos en esa cadena de progresivo reconocimiento de derechos. En 1989, la Organización Internacional del Trabajo (OIT) adoptó el Convenio sobre los Derechos de los Pueblos Indígenas y Tribales (Convenio núm. 169 de la OIT) ${ }^{4}$. Desde entonces, el Convenio ha sido ratificado por veinte países. En 2007, la Asamblea General de las Naciones Unidas adoptó la Declaración de las Naciones Unidas sobre los Derechos de los Pueblos Indígenas (A/RES/61/295)5. La adopción supuso la culminación de años de discusiones y negociaciones entre gobiernos y pueblos indígenas, además de constituir un logro histórico que aporta a la comunidad internacional un marco común para la realización de los derechos de los pueblos indígenas. Los instrumentos internacionales de protección de sus derechos parecen consolidaos ${ }^{6}$. El reto estriba ahora en que desde los Estados se transpongan las normas internacionales, a la vez que se reconozcan y garanticen, bien sea mediante las nuevas Constituciones (o reformas cons-

\footnotetext{
${ }^{1}$ Agradezco la colaboración en este trabajo del Profesor Dr. D. Elder Antonio Lunardi, profundo conocedor de la cultura, antrología y sistema de organización de los indios, así como de la difícil situación que tienen que vivir muchas de las comunidades indígenas en la actualidad. Durante sus años de trabajo en la FUNAl, ha sido un verdadero defensor de los derechos de los indios. Mi reconocimiento a su esfuerzo.

2 Para profundizar en este periodo, vid. PÉREZ LUÑO, A. E. La polémica sobre el Nuevo Mundo. Los clásicos españoles de la Filosofía del Derecho, Madrid, Trotta, 1992.

${ }^{3}$ Convendría partir de unas precisiones terminológicas, ya que aludiremos indistintamente a cuatro denominaciones. Cada una de estas denominaciones tiene su entidad y significado propio y distintivo de las otras: indios, indígenas, y pueblos indígenas: a) Indio es cualquier persona reconocida por su comunidad y que tenga relaciones histórico-sociales con las sociedades precolombinas. La denominación general de indio engloba a cientos de comunidades con una gran diversidad cultural. (VIVEIROS DE CASTRO, Eduardo. Rio de Janeiro: Beco do Azougue, 2008, p. 132; b) Los indígena son pueblos o sociedades precolombinas. Es decir, pueblos que ya vivían en las tierras americanas antes del descubrimiento llevado a cabo por Colón. (PORTELA, Fernando y MINDLIN, Betty. A questão do índio. São Paulo: Ática, 1991, p. 12); c) El Convenio no169 de la OlT establece la autoidentidad indígena como criterio esencial para la definición de los pueblos, sujetos al Convenio, previniendo cualquier intento por parte del Estados o de grupos sociales de negar una identidad al pueblo indígena.

${ }^{4}$ AA.W., Los Derechos de los pueblos indígenas y tribales en la práctica. Una guía sobre el Convenio núm. 169 de la OIT, http://www.lo.org/wcmsp5/ groups/public/---ed_norm/---normes/documents/publication/wcms_113014.pdf (Acceso el 15.04.2014); también, vid. BELLOSO MARTíN, Nuria. "Los derechos de los pueblos indígenas como derechos emergentes", en GORZEVSKI, Clovis (Organizador), Direitos Humanos e participacâo politica. Vol. V, Porto Alegre, (Brasil), Imprensalivre, 2014, pp. 59-110.
}

${ }^{5}$ Declaración de la Asamblea General de Naciones Unidas sobre los Derechos de los pueblos indígenas. Disponible en:http://www.un.org/esa/socdev/ unpfii/documents/DRIPS_es.pdf; (Acceso el 28.02.2015)

${ }^{6} \mathrm{~A}$ nivel internacional, durante las últimas dos décadas se han promulgado textos y normativa internacional para hacer efectiva la protección y garantías de los derechos humanos de los pueblos indígenas, entre las que destacamos: a) Aprobación del Convenio No. 169 de la OIT; b) Primer y Segundo Decenio Internacional los Pueblos Indígenas del Mundo; c) Creación del UNPFII; d) Nombramiento del Relator Especial sobre la situación de los derechos humanos y las libertades fundamentales de los indígenas; e) Creación del Grupo Interinstitucional de Apoyo sobre Cuestiones Indígenas (Inter-Agency Support Group on Indigenous Issues); f) Adopción de la Declaración de las Naciones Unidas sobre los derechos de los pueblos indígenas por la Asamblea General en septiembre de 2007. 
titucionales) de América Latina7, los derechos indígenas en cada país.

Junto al impulso que el Derecho internacional de los derechos humanos estos dos relevantes instrumentos legislativos, hay que hacer especial mención a las propuestas del pluralismo crítico y de la ciudadanía multicultural.

En los últimos lustros, la fuerza de la reaparición de los indígenas en Latinoamérica, ha conmovido las convicciones tradicionales de los juristas y los propios sistemas normativos. "La idea de que en un país existe un solo sistema jurídico ha sido contestada a lo largo y ancho del territorio de la Teoría del Derecho, por el Ilamado pluralismo jurídico. Especialistas en la materia, como Antonio Carlos Wolkmer, han ayudado a configurar un marco jurídico-político-social apoyado en el pluralismo, del que los pueblos indígenas son uno de los protagonistas. Los sistemas normativos indígenas, poco a poco, han ido ocupando su lugar en las respectivas Constituciones de los diversos países. Hasta ahora, los antropólogos y los historiadores han sido quienes han dedicado una mayor atención al tema. Por parte de los juristas no se percibía un interés acusado. Sin embargo, cada vez son más las voces que proponen que en las Facultades de Derecho se abran cátedras de derecho indígena, so pena de quedar completamente desactualizadas respecto del movimiento histórico encabezado por los propios indígenas"8.

Los derechos indígenas suponen un reto para el constitucionalismo latinoamericano en cuanto a su afectación a los derechos humanos ${ }^{9}$, principalmente en cuanto a su relación con el derecho a la igualdad. Hay minorías, grupos diferenciados que, precisamente, para lograr que el principio de igualdad sea una realidad, deben hacerlo a partir de la diferencia y constituirse como "ciudadanos diferenciados". Las Constituciones que se enmarcan en el nuevo constitucionalismo latinoamericano, han acogido los derechos indígenas en un planteamiento que excede el modelo de Estado multiculturalista, orientándose hacia un Estado plurinacional. Ello permite que los derechos indígenas encuentren más fácilmente acomodo, sin el temor a que se les ofrezca una asimilación o tutelaje.

\section{La problemática relación entre derechos universales/ derechos diferenciados}

En el ámbito jurídico se han ido sucediendo corrientes y tendencias. Actualmente, algunos movimientos doctrinales tienden a demostrar la evolución hacia la denominada "hipermodernidad", superando la anterior corriente posmoderna que criticó a la propia modernidad. ${ }^{10}$ Según Lipovetsky, la posmodernidad sólo ha sido una etapa de transición, porque ya no se trata de salir de la tradición sino de modernizar la propia modernidad. Por ello, la hipermodernidad se propone un retorno a los derechos humanos, a los valores y a la ética, que deja de estar vinculada al sacrificio -como sucedía en la modernidad- y se adapta a la autonomía individua-

\footnotetext{
${ }^{7}$ Clavero subraya que se trata de "superar una indiferencia constitucional y una iniquidad social" [...] "un derecho, el indígena, se antepone mientras que una referencia, la constitucional, no sólo se amplifica, sino que también se relativiza." (CLAVERO, Bartolomé. Geografía jurídica de América Latina. Pueblos indígenas entre constituciones mestizas, México: Siglo XXI, 2008). También, vid. CLAVERO, Bartolomé. "Estado plurinacional: aproximación a un nuevo paradigma constitucional latinoamericano". En ROJAS, Rafael (Ed.) De Cádiz al Siglo XXI: doscientos años de constitucionalismo en Hispanoamérica. México: Taurus-Centro de Investigación y Docencia Económicas, 2012.

${ }^{8}$ CORREAS, Oscar, (Coordinador), Derecho Indígena Mexicano I, Coyoacán México: CEIICH-NAM/CONACYT/Ediciones, 2007.

${ }^{9}$ MARÉS DE SOUZA FILHO, Carlos Frederico. Os Direitos Humanos e os povos indígenas. Disponible en: ‘http://www.dhnet.org.br/direitos/sos/indios/mares. html.(Acceso el 26-12-2014).

${ }^{10}$ Como bien apunta el profesor Pérez Luño, hubo tesis centradas en la abolición del proyecto de la modernidad: "racionalidad, universalidad, cosmopolitismo, igualdad que consideraban caducos (...) Las normas jurídicas, generales y abstractas, corolario de exigencias éticas universales, fueron cuestionadas en nombre de las preferencias particularistas fragmentarias; la propia legitimación ética del derecho y de la política, basada en principios consensuales universales llegó a considerarse un ideal vacío y sospechoso de encubrir uniformismos totalitarios" (PÉREZ LUÑO, Antonio-Enrique. Trayectorias contemporáneas de la Filosofia y la teoria del Derecho. Sevilla: Grupo Nacional de Editores, 2003, p.15 y ss.
}

${ }^{11}$ LIPOVETSKY, G. Los tiempos hipermodernos. Barcelona: Anagrama, 2006, p.105. 
lista. ${ }^{11}$ También Touraine apuesta por la idea de una sociedad hipermoderna, por la necesidad de reinterpretar la modernidad y por un principio integrador que restablezca la conexión entre individuo y colectividad ${ }^{12}$.

Algunos autores consideran que a partir de la universalidad de los derechos, no es necesario descender a otros tipos de categorías tales como derechos diferenciados, derechos de las minorías u otros. Consideran que es suficiente con los derechos de las personas consagrados en las Constituciones contemporáneas, máxime cuando los grupos diferenciados y las minorías no pretenden otros derechos distintos a los que las Constituciones conceden a sus ciudadanos ${ }^{13}$.

\subsection{Precisiones conceptuales sobre la universalidad de los derechos}

Para delimitar el concepto de universalidad conviene comenzar contraponiéndolo al de generalidad. Como ha precisado de Castro Cid, "universalidad" equivale a la predicabilidad constitutiva respecto de todos los componentes o individuos de un determinado conjunto o universo lógico (clase, especie, género). En cambio, "generalidad" consiste en la predicabilidad respecto de un número de componentes o individuos de un determinado conjunto o universo lógico, que puede ser notoriamente amplio pero que en ningún caso cubre la totalidad lógica de tales componentes. Es decir, puede definirse la "universalidad" como una generalidad lógico-ontológica del todo y la "generalidad" como una universalidad meramente estadística de una parte del todo ${ }^{14}$.

Las perspectivas o tipos de universalidad son variados: la dimensión subjetiva se ocupa de la universalidad en razón de los titulares de derechos, proclamando la predicabilidad de los derechos humanos respecto de la totalidad de los posibles titulares; si se afirma la universalidad en su dimensión objetiva, se está sentando la tesis de que los derechos humanos tienen la capacidad de dar cobertura y protección a todos aquellos intereses o aspiraciones que puedan llegar a ser considerados dignos de obtenerlas; la dimensión cultural indica que hay una común aceptación de los derechos humanos por parte de las diferentes tradiciones culturales; la dimensión cronológica implica la validez de los derechos humanos como resistente al paso del tiempo; y, por último, la dimensión política implica que todos los niveles y ámbitos de organización jurídica y política quedan sometido al influjo de los derechos humanos ${ }^{15}$.

El carácter universal de los derechos implica que se trata de derechos que corresponden a todos los hombres y que tienen validez para todos los tiempos. Sin embargo, esa universalidad ha sido negada a menudo, tanto por motivos empíricos como por consideraciones de naturaleza racional. En el plano empírico se señala que no existe una vigencia universal de los mismos, ya que no se atribuyen a todos los sujetos por igual, no han tenido vigencia en todas las épocas, no cubren

\footnotetext{
12 TOURAINE, Alain. “¿Después del posmodernismo?... La modernidad” en RODRíGUEZ MAGDA, R.M. y ÁFRICA VIDAL, M.C. (edts.) Y después del posmodernsimo ¿qué?, Barcelona: Anthropos, 1988, p.23 ss.

${ }^{13}$ Esta posición es sustentada por E. Fernández en la medida en que no le gusta el término "derechos de las minorías" porque parece indicar "derechos especiales para personas especiales" al margen de la idea de derechos fundamentales como derechos de todos los seres humanos. FERNÁNDEZ, Eusebio. "Derechos de la minorías culturales y de pensamiento" en SAUCA, José Mํ. Derechos de las minorías y grupos diferenciados. Madrid: Escuela Libre Editorial, 1994, pp.297-213. Soriano, acertadamente, advierte que es cierto que la mayor parte de estos derechos coinciden. Sin embargo, hay derechos de las minorías específicos que no coinciden con los derechos de la mayoría. SORIANO, Ramón. Los derechos de las minorías. Sevilla: Editorial MAD, 1999 , p.25. Soriano advierte que cada minoría presenta sus reivindicaciones peculiares de sus derechos. No todas las minorías necesitan los mismos derechos y el mismo tratamiento jurídico porque sus necesidades y situaciones difieren. No están igual los negros en USA que las poblaciones aborígenes de los antiguos Estados colonizadores que reivindican el reconocimiento particular y diferenciado de su cultura y sistema de vida. Según Soriano, los derechos de las minorías admiten una clasificación muy generalista: a) derechos de autonomía como tales minorías; b) derechos de diferenciación cultural; y c) derechos a la igualdad (Ibidem, p.21).

${ }^{14}$ CASTRO CID, Benito de, "La universalidad de los Derechos humanos: ¿Dogma o mito?" en Derechos y Libertades, nº5, Universidad Carlos III de MadridBOE, 1995, p.387.

${ }^{15}$ CASTRO CID, Benito de, "La universalidad de los Derechos humanos: ¿Dogma o mito, cit, pp.389-391.
} 
todas las necesidades básicas y no han sido asumidos por todas las culturas ni por todos los regímenes políticos. En el plano racional, se proclama que todos los sistemas de valores y creencias, la "religión" o la "ideología" de los derechos humanos tiene un alcance delimitado por la proyección de sus propias circunstancias históricas y por el contexto cultural en el que nace y subsiste.

Hay datos que parecen contraindicar su universalidad pues son numerosas las divergencias: conceptuación, fundamentación, importancia jerárquica, observancia, etc. El pretendido principio de la universalidad subjetiva quiebra con frecuencia, Por ejemplo, en el reconocimiento de los "derechos de grupo" (es decir, derechos atribuidos a conjuntos determinados de sujetos en función de las peculiares circunstancias en que se realiza su existencia, como pueda ser en el caso de los indios) parece ser un signo manifiesto de la ausencia de la presunta universalidad subjetiva, puesto que esta sectorialización de los derechos humanos, a partir del reconocimiento de diferentes categorías de personas constituye, lo mismo que la sectorialización por el diferente contenido de los derechos (civiles, políticos, económicos, culturales, de solidaridad), una flagrante contraindicación del tradicional postulado de universalidad, de corte individualista, basado en el principio de una esencial igualdad entre todos los sujetos. La defensa de la universalidad cultural -que también podemos aplicar a los indioschoca también con datos que la contradicen. Es evidente que la vivencia diaria de los derechos humanos (concepción, aceptación y ejercicio efectivo) está profundamente mediatizada por la presión de las diferencias ideológicas y culturales. Y, al mismo tiempo, puede comprobarse que no existe consenso universal sobre la importancia o primacía que corresponde a los diferentes derechos o grupos de derechos ${ }^{16}$.
Pero si hay datos que contraindican la universalidad también hay otros datos que respaldan o confirman la universalidad. La base de la atribución de la universalidad que la concepción tradicional (de orientación iusnaturalista) proclama respecto de los derechos humanos está en su directa vinculación con la naturaleza humana o con la dignidad personal de los hombres. De Castro reconduce la tesis de la universalidad de los derechos humanos hacia el postulado racional de una esencia humana idéntica y única para todos los individuos (por tanto, universal) o de una idéntica capacidad de razonamiento moral, puesto que solo la igualdad esencial de todos los sujetos reconocidos como titulares de derechos puede sustentar la afirmación de su universalidad ${ }^{17}$.

Por su parte, De Lucas ${ }^{18}$ pone especial énfasis en las etapas de evolución de los derechos humanos a la hora de contraponer la universalidad de los derechos humanos y el relativismo ético y cultural. Concretamente, el proceso de especificación tiene en cuenta las diferencias de algunos grupos (o individuos) como suficientemente relevantes para reconocerlos como titulares de derechos específicos. Se trata de características tales como determinadas situaciones sociales o culturales (las minorías, como puedan ser las comunidades indígenas), físicas (minoría de edad, discapacidades), o la especificidad del lugar que se ocupa en algunas relaciones sociales (consumo, servicios públicos, etc.).

La crítica más poderosa al carácter universal de los derechos humanos es la que procede del relativismo cultural, que pone en duda que estemos universalmente de acuerdo cuando hablamos de derechos. No cabe duda de que hay diferencias básicas entre la tradición occidental y las de sociedades como la japonesa, o con comunidades indígenas, por ejemplo, que es el tema que nos ocupa.

\footnotetext{
${ }^{16}$ CASTRO CID, Benito de, Ibidem, pp.394-395.

${ }^{17}$ CASTRO CID, Benito de, Ibidem, p.401.

${ }^{18}$ LUCAS, Javier de, "Para una discusión de la nota de universalidad de los derechos. (A propósito de la crítica del relativismo ético y cultural)", en Derechos y Libertades, nํㅜ, Universidad Carlos III de Madrid-BOE, 1994, pp.259-312.
} 
Puesto que hay una pluralidad cultural, ¿No debería haber una pluralidad normativa? Porque, ¿Cuál es el criterio para defender la superioridad de un código sobre otro? ¿Qué es lo que permite erigir uno de ellos en criterio, en modelo, en supracódigo al que han de ajustarse los demás que, por consiguiente han de ser evaluados por aquél? ¿Cómo presentar y justificar la homogeneidad social? ¿Equivale simplemente a su formulación como uniformidad, como asimilación impuesta, aunque sea por la vía de enunciarla como condición para el acceso a la ciudadanía y los derechos? Como se ha señalado, el primer efecto perverso de un planteamiento de homogeneidad por imposición es que, casi, inevitablemente, al menos a largo plazo, genera un modelo de respuesta resistente, que se convierte en una espiral $\sin$ fin $^{19}$.

Son muchos los autores que han insistido en la dificultad que comporta el proyecto de una sociedad multicultural o multiétnica. Ciertamente, por encima de declaraciones que puedan ser consideradas bienintencionadas o voluntaristas y/o ingenuas, lo que resulta claro es que la conciliación de universalismo y respeto a la diversidad cultural está lejos de ser una tarea sencilla. Los elementos de la "identidad colectiva" que aumentan su vulnerabilidad a la coacción y al engaño deben ser rechazados. Pero tampoco se trata de conservar lo puramente trivial y "folclórico" de esas minorías (vestuario, gastronomía, etc.). Tampoco se trata de que por mucho que debamos respetar, comprender y juzgar desde los propios universos simbólicos, esto nos obligue a aceptar como derecho cualquier demanda y menos aún las que carezcan de argumentos para justificar tal pretensión, como pudiera ser la antropofagia, o la consideración de la mujer o los niños como no-persona.

Se trata de comprender y valorar la diversidad, lo cual no significa aculturación, asimilación for- zosa e impuesta, sino integración efectiva desde la libre discusión: "no hay otro camino hacia lo universal que el que pasa por lo particular".

\subsection{Los indios como sujetos de derechos humanos}

El estudio de la teoría de los derechos humanos, se puede realizar mediante dos tipos de análisis: en primer lugar, la teoría jurídica de esta categoría de derechos, que tiene que ver con el conjunto de tratados, convenciones y legislaciones cuyo objeto es la definición de estos derechos, así como la regulación de los mecanismos, internacionales y nacionales, garantes de los derechos fundamentales de la persona humana; por otro lado, la teoría de los derechos humanos trata, también, del análisis de los Ilamados fundamentos de estos derechos, tema que en la actualidad se destaca en la filosofía social y política contemporánea. La teoría de los derechos humanos implica, así, la complementariedad necesaria entre la reflexión teórica y la práctica, ya que no tendría sentido el análisis teórico, abstracto, que no tuviese en cuenta los problemas reales que afectan cotidianamente a la persona humana en este final de siglo (discriminaciones sociales, políticas y religiosas, falta de libertad, limpieza étnica, miseria, analfabetismo, etc.), y tampoco aceptar como verdad última, universal y acabada, las diversas situaciones sociales del mundo contemporáneo. Tanto la teoría como la práctica de los derechos humanos tienen por objetivo superar estas situaciones sociales en términos de valores y normas, que aseguren la dignidad de la persona humana. ${ }^{20}$

El vínculo entre los derechos específicos y los derechos universales que los presenta como opuestos se desarrolla como portadora de una visión empobrecida por la complejidad de su relación. Mucho más fecundo parece estar siendo el re-

\footnotetext{
${ }^{19}$ LUCAS, Javier de, "Para una discusión de la nota de universalidad de los derechos. (A propósito de la crítica del relativismo ético y cultural)", cit, p.288.

${ }^{20}$ CELSO, D. A. M. Direitos humanos e conflitos armados. Rio de Janeiro: Renovar, 1997.
} 
considerar las probabilidades de las diferentes combinaciones entre los derechos universales individuales y los derechos a las especificidades culturales. En torno a esta cuestión se conforman los probables horizontes políticos con respecto a la construcción de los derechos humanos en un orden social cada vez más globalizado y cada vez más desigual. La combinación concreta y política de las relaciones y tensiones entre los derechos universales y los derechos a las diversidades culturales muestra sus diferentes y múltiples dimensiones, y requiere un replanteamiento de la solución fácil de escoger entre los derechos individuales universales y los derechos a la especificidad cultural. Cómo combinarlos y como respetarlos mutuamente es la perspectiva más fecunda, y el mayor desafío en el campo de los derechos humanos internacionales. ${ }^{21}$

El empleo de la expresión "derechos humanos" refleja esta comprensión y las consecuentes ambigüedades conceptuales con las que ha sido utilizada. La expresión puede referirse a las situaciones sociales, políticas y culturales que se diferencian entre sí, lo que significa a menudo manifestaciones emotivas en contra de la violencia y de la injusticia; en realidad, la multiplicidad de los usos de la expresión demuestra, sobre todo, la falta de fundamentos comunes que puedan contribuir a universalizar su significado y, por consiguiente, su práctica. Un número significativo de autores ha tomado la expresión "derechos humanos" como sinónimo de "derechos naturales": Ios primeros serían la versión moderna de estos últi- mos; otros, utilizan la expresión como un conjunto de derechos que así se encuentran definidos en los textos internacionales y legales, y que no impide que "los nuevos derechos sean consagrados en el futuro". Algunos, también, se refirieron a la idea de los derechos humanos como normas generales, relativas a la práctica jurídica, que se expresarían a través de los principios generales del derecho. ${ }^{22}$

No vamos a extendernos en el tema de las diversas etapas de evolución de los derechos humanos a lo largo de la historia pues excedería los límites que nos hemos fijado para llevar a cabo nuestra investigación. Nos vamos a limitar a destacar dos aspectos: uno, el de la relevancia de la protección de los derechos ${ }^{23}$ : si no están garantizados de nada sirve contar con extensos textos en los que se los enumere de manera prolija y detallada. En segundo lugar, la etapa actual de evolución de los derechos humanos en la que nos encontramos, la de especificación de los derechos humanos -junto con la de la internacionalización ${ }^{24}$, constituye el marco en el que se pueden centrar las condiciones de unos titulares específicos que se encuentran en una situación peculiar y necesitan una protección y unas medidas especiales: los indios.

Desde el siglo XVII, los indios y sus tierras habrían sido considerados como algo susceptible de conquista y apropiación. A partir de ahí, los blancos comenzaron a legislar sobre ellos, estableciendo así las leyes con el uso de la fuerza, la esclavitud

\footnotetext{
${ }^{21}$ CUNHA, C. "A noçāo de direito costumeiro e os direitos indígenas na Nova Constituiçāo do Brasil". América Indígena XLIX (2), 1989.

22 LAFER, Celso. A Reconstruçāo dos Direitos Humanos, São Paulo: Companhia das Letras, 1991.

${ }^{23}$ Como sostiene Bobbio, en A era de los derechos, P. 25, "el problema que tenemos delante de nosotros no es filosófico, sino jurídico y, en un sentido más amplio, político. No se trata de saber cuáles y cuántos son estos derechos, cuál es su naturaleza y su fundamento, si son derechos naturales o históricos, absolutos o relativos, sino cual es el modo más seguro para garantizarlos, para impedir que, a pesar de las solemnes declaraciones, sean continuamente violados".

${ }^{24}$ Seguimos aquí la clasificación inicialmente expuesta por N. Bobbio y que G. Peces-Barba ha explicado más detalladamente (Vid. PECES BARBA MARTíNEZ, Gregorio. Curso de derechos humanos. Madrid: Eudema, 1995). La etapa de especificación de los derechos humanos consiste en el paso gradual hacia una ulterior determinación de los sujetos titulares de los derechos así como del contenido de los mismos. Este proceso supone una ruptura con el modelo racional y abstracto, y una cierta aproximación al modelo pragmático inglés, al completar la idea de los destinatarios genéricos, los hombres y los ciudadanos, con la de las personas situadas como mujeres, niños, administrados, consumidores, y al matizar también los contenidos con la aparición de nuevos derechos, vinculados al medio ambiente, a la paz, al desarrollo, etc. La especificación puede ser por razón de los titulares (condición social o cultural de personas que se encuentran en situación de inferioridad y necesitan una protección especial: mujer, emigrante; condición física de personas en situación de inferioridad: niños, personas con minusvalías físicas o psíquicas; situación que ocupan personas en determinadas relaciones sociales: hombre situado como consumidor, como usuario); Por los contenidos (medio ambiente y protección del entorno natural; derecho al desarrollo; derecho a la paz).
} 
y la guerra y como resultado de ello el etnocidio y genocidio, la desestabilización social religiosa y la destrucción de su cultura. ${ }^{25}$

En cierta forma, el proceso de colonización persiste actualmente aunque con un nuevo disfraz ${ }^{26}$. Ahora, ya no por la imposición del trabajo servil, o por la fuerza, sino a través de la visión del indio como ser incompleto, atrasado e incapaz, todo ello con el ánimo de justificar el control del Estado sobre su vida y su destino. Esta perspectiva debe cambiar porque de lo contrario, se corre el riesgo de perder la riqueza y la pureza de los primitivos habitantes de nuestras tierras. Todo ello bajo el manto constitucional del Estado democrático de derecho y el principio de dignidad de la persona humana, que no debe ser una letra muerta sino un marco de una sociedad pluralista, igualitaria y fraterna, respetando las diversidades y libre determinación de un pueblo que resiste por su cultura e identidad.

Gargarella advierte que el denominado "nuevo" constitucionalismo latinoamericano no ha conllevaedo las innovaciones que se habían augurado:

Las "nuevas" Constituciones latinoamericanas se mantienen ajustadas al doble molde originario. Se trata de Constituciones con "dos almas": la primera, relacionada con una estructura de poderes que sigue respondiendo a concepciones verticalistas y restrictivas de la democracia, como las que primaban en el siglo XIX; y la segunda, de tipo social, relacionada con la estructura de derechos que se forjara a comienzos del siglo XX. A esta combinación, el último constitucionalismo latinoamericano le agregó pocos cambios, que facilitaron las reelecciones presidenciales, y en todo caso expandieron algo más las ya ambiciosas listas de derechos: si las de comienzos de siglo habían procurado incorporar a la "clase trabajadora" en la Constitución (más no sea a través de las declaraciones de derechos), las de finales de siglo comenzaron a hablar de derechos indígenas, multiculturales, o de género. Cuestiones que no habían sido tematizadas por las Constituciones anteriores. ${ }^{27}$

Por tanto, se han limitado a hablar de "derechos indígenas" pero sin dotarles de una regulación postconstitucional que hiciera efectivo los derechos reconocidos constitucionalmente. Gargarella se lamenta de que:

el "nuevo constitucionalismo latinoamericano" reproduce las viejas estructuras autoritarias que recibimos en legado de los siglos XVIII y XIX. Me interesa afirmar que no hay proyecto democrático y de avanzada bajo organizaciones de poder concentradas en Ejecutivos o monarcas, que representan la negación política de la democracia que declaman. Y me interesa insistir, ante todo, en esta idea: la contradicción que las nuevas Constituciones establecen entre el modo en que organizan el poder (estilo siglo XIX) y el modo en que definen derechos (estilo siglo XXI) no nos habla de una relación desafortunada, con la que hay que aprender a convivir, sino de una tensión que amenaza la vida misma de los derechos que esas Constituciones proclaman. ${ }^{28}$

Se ha expulsado los indios de su hábitat natural a través de la antigua cultura de la política integracionista, que dio lugar a la aculturación de las poblaciones indígenas, sin respetar sus usos y costumbres ricas y diferentes, sofocando y provocando a descaracterización étnica que, con el tiempo, ha provocado una ola de suicidios

\footnotetext{
${ }^{25}$ Vid. YRIGOYEN FAJARDO, R.Z. "El horizonte del constitucionalismo pluralista: del multiculturalismo a la descolonización” en Rodríguez Garavito, C. (Coordinador) El Derecho en América Latina. Un mapa para el pensamiento jurídico del siglo XXI, Buenos Aires, Siglo XXI Editores, 2011, pp. 139-160. Disponible en: ‘http://www.justiciaglobal.net/files/actividades/fi_name_recurso.8.pdf. (Acceso el 05.06.2016). También, en la msima obra, vid. SIEDER, R., "Pueblos indígenas y derecho(s) en América Latina, pp.303-322.

${ }^{26}$ JUNQUEIRA, Carmen. Antropologia Indígena: uma introduçāo, história dos povos indígenas no Brasil. São Paulo: EDUC-Editora da PUC, 1991, p. 73.

${ }^{27}$ GARGARELLA, R., "El nuevo constitucionalismo latino-americano", en Sinpermiso, p.2. Disponible en: http://www.sinpermiso.info/textos/el-nuevo-constitucionalismo-latinoamericano. (Acceso el 02.07.2016). Para profundizar en el tema, vid. GARGARELLA, R., La sala de máquinas de la Constitución: Dos siglos de constitucionalismo en América Latina (1810-2010), Buenos Aires, Katz Editores, 2014.

${ }^{28}$ GARGARELLA; R., "El nuevo constitucionalismo latino-americano", cit.
} 
de muchas etnias, ante la falta de perspectiva y abandono por parte del Estado, que hace dejación de sus deberes constitucionales.

La teoría sociopolítica ha destacado que la politización reciente de las cuestiones étnicas procede de una confluencia de al menos tres aspectos que actúan de manera interconectada: (a) el desarrollo del Derecho Internacional, que caracteriza los derechos indígenas como parte específica de los Derechos Humanos; (b) el surgimiento de los movimientos indígenas que operan, a nivel nacional e internacional, cada vez más como grupos de interés dentro de la sociedad civil y en los espacios públicos democráticos, presionando por un conjunto de derechos colectivos; y (c) los procesos recientes de reformas constitucionales en varios países, reconociendo -al menos en principio- el carácter multiétnico de sus sociedades. ${ }^{29}$

En un primer momento tales derechos fueron alcanzados no en cuanto grupo étnico especifico, sino como parte de una política de universalización de los derechos del hombre, donde todos eran considerados iguales y merecedores del mismos derechos, sin pero tener en consideración las especificidades culturales de cada grupo étnico. Será sólo con las permanentes reivindicaciones y luchas indígenas que aproximadamente, en los últimos 50 años, tales derechos se hayan ido conquistando como derechos diferenciados, específicos de la ciudadanía étnica, como el derecho a la autodeterminación, a la educación y a la salud intercultural y al respeto de las diferencias.

Wolfgang Sarlet ${ }^{30}$ apunta que los derechos de los indios son considerados derechos fundamentales por el hecho de que están presentes en el cuerpo del texto constitucional. Los derechos fundamentales se aplican a aquellos derechos del ser humano, reconocidos y positivados en la esfera del derecho constitucional positivo de un Estado determinado, al mismo tiempo que la expresión 'derechos humanos' guarda relación con los documentos de derecho internacional, por referirse a las posiciones jurídicas que se reconocen al ser humano como tales $e$ independientemente de su vínculo con un cierta orden constitucional y que, por lo tanto, aspiran a la validez universal, para todos los pueblos y tiempos, de tal manera que revelan un incuestionable carácter supranacional - internacional.

El informe sobre Derechos Humanos y Libertades Fundamentales de los Indígenas, de Stavenhagen ${ }^{31}$ resume los diversos casos de violación flagrante de los derechos indígenas y ejemplos que describen el claro desequilibrio entre los niveles de la legislación internacional sobre los derechos indígenas, el constitucionalismo latinoamericano y la legislación ordinaria. Se llega a la conclusión que hay una grave incoherencia legal y, a menudo, falta una legislación reglamentaria y secundaria imprescindible. También se observa una brecha entre la implementación de la legislación existente y la práctica administrativa, jurídica y política, cuyas raíces son varias: hay poca participación indígena en la formulación y aplicación de las leyes, la falta de seguimiento de la aplicación de las leyes y de las políticas públicas y, especialmente, hay un aparato burocrático estatal inadecuado, lento, con un funcionamiento que no se ajusta a las demandas multiculturales y que lleva aún el rancio asimilacionismo, perjudicial para abordar los derechos de las minorías étnicas.

\subsection{El contenido de los derechos humanos de los indios}

Entre los principales derechos de los pueblos indígenas cabe destacar el derecho a la igualdad,

\footnotetext{
${ }^{29}$ SIEDER, R. Multiculturalism in Latin America: Indigenous rights, diversity and democracy. Inglaterra: Palgrave/lLAS, 2002.

${ }^{30}$ WOLFGANG SARLET, Ingo. A Eficácia dos Direitos Fundamentais. $2^{\underline{a}}$ ed. Porto Alegre: Livraria do Advogado, 2001.

${ }^{31}$ STAVENHAGEN, R. Los pueblos indígenas y sus derechos: Informes temáticos del relator especial sobre la situación de los Derechos Humanos y las libertades fundamentales de los pueblos indígenas del Consejo de Derechos Humanos de la Organización de las Naciones Unidas (2002-2007).
} 
el derecho a la autodeterminación y los derechos colectivos $^{32}$, a los que vamos a hacer referencia seguidamente:

\section{a) Derecho a la igualdad:}

Según las normas internacionales de derechos humanos, los pueblos indígenas, al igual que todos los seres humanos, tienen derecho a gozar de todos los derechos humanos y libertades fundamentales incluidos tanto derechos civiles y políticos como derechos económicos, sociales y culturales, tales como los derechos a salud y educación. Tienen derecho a igual trato y a beneficiarse, como cualquier ciudadano del estado en que viven, del desarrollo económico y del progreso de otra índole. Estos derechos son aplicables por igual a los hombres y las mujeres, a los niños y los adultos. Sin embargo, en la práctica los pueblos indígenas a menudo no han sido tratados de igual manera y enfrentan exclusión social. En ciertos casos, brindar las mismas oportunidades que son brindadas a otros puede no ser lo suficiente para asegurar que la situación de los pueblos indígenas mejoren hasta el nivel de otros grupos. El asegurar que los pueblos indígenas tengan oportunidades iguales puede requerir que los estados tomen medidas especiales o focalizadas para compensar injusticias y desventajas históricas, incluida la doble discriminación enfrentada por las mujeres indígenas, un principio que también constituye uno de los objetivos del Segundo Decenio Internacional de los Pueblos Indígenas del Mundo ${ }^{33}$.

El propósito de las medidas positivas especiales es llevar las condiciones de vida de los pueblos indígenas al mismo nivel de aquellas de otros en la sociedad. También deben reflejar las aspiraciones de los pueblos indígenas de proteger, mantener y desarrollar sus culturas e identidades, costumbres, tradiciones e instituciones.

\section{b) Derecho a la autodeterminación:}

Los pueblos indígenas tienen derecho a la autodeterminación ${ }^{34}$. La Declaración de las Naciones Unidas sobre los derechos de los pueblos indígenas afirma en su artículo tercero que "Los pueblos indígenas tienen derecho a la libre determinación. En virtud de ese derecho determinan libremente su condición política y persiguen libremente su desarrollo económico, social y cultural." Este artículo se basa en el Artículo 1 común del Pacto internacional de derechos civiles y políticos y el Pacto internacional de derechos económicos, sociales y culturales.

Los representantes de los pueblos indígenas y los Estados han discutido a profundidad las implicaciones del derecho a la autodeterminación. Los estados han expresado preocupaciones relativas a su integridad territorial debido a posibles demandas de independencia de parte de los pueblos indígenas ${ }^{35}$.

Los pueblos indígenas han subrayado su deseo de determinar su propio desarrollo, bien estar y futuro en concordancia con sus modos de vida y culturas. Una comprensión equilibrada ha sido encontrada en la Declaración de las Naciones Unidas sobre los Derechos de los Pueblos Indígenas.

\footnotetext{
32 Junto a estos derechos cabría destacar también el derecho a la educación, a la salud, al desarrollo y otros muchos. Vid. Directrices sobre los asuntos de los Pueblos indígenas. Grupo de las Naciones Unidas para el Desarrollo, 2008. Disponible en «http://www2.ohchr.org/english/issues/indigenous/docs/ UNDG-Directrices_pueblos_indigenas.pdfs (Acceso el 11-05-2015).

33 En este sentido, la Recomendación General No. 23: La situación de las poblaciones indígenas del Comité para la Eliminación de la Discriminación Racial subraya esta situación y propone varias medidas para su mejoramiento (disponible en: http://www.unhchr.ch/tbs/doc.nsf/ (Symbol)/2a12ea8905164c6e8025684a00545d05?Opendocument).

${ }^{34}$ La Recomendación General No. 21: Derecho a la libre determinación del Comité para la Eliminación de la Discriminación Racial hace referencia especial a la autodeterminación de los pueblos indígenas (disponible en http://www.unhchr.ch/tbs/doc.nsf/(Symbol)/b352135254eb2c468025652b005a4a64?0pendocument).

${ }^{35}$ El Artículo 46, Párrafo 1, de la Declaración sobre los derechos de los pueblos indígenas declara: "Nada de lo contenido en la presente Declaración se interpretará en el sentido de que confiere a un Estado, pueblo, grupo o persona derecho alguno a participar en una actividad o realizar un acto contrarios a la Carta de las Naciones Unidas, ni se entenderá en el sentido de que autoriza o alienta acción alguna encaminada a quebrantar o menoscabar, total o parcialmente, la integridad territorial o la unidad política de Estados soberanos e independientes."
} 
El derecho a la autodeterminación puede expresarse por medio de: i) Autonomía o autogobierno en cuestiones relacionadas con sus asuntos internos y locales, así como medios de financiar sus funciones autónomas. En otros casos, los pueblos indígenas buscan las condiciones para la autogestión; ii) Respeto por el principio de consentimiento libre, previo e informado. Este principio implica que exista una ausencia de coacción, intimidación o manipulación, que el consentimiento haya sido buscado con suficiente antelación a cualquier autorización o inicio de actividades, que se muestre respeto por los requisitos de tiempo de los procesos indígenas de consulta/consenso y que se suministre información plena y comprensible con respecto al impacto probable; iii) Participación plena y efectiva de los pueblos indígenas en cada etapa de cualquier acción que pueda afectarles directa o indirectamente. La participación de los pueblos indígenas puede ser a través de sus autoridades tradicionales o de una organización representativa. Esta participación también puede tomar la forma de co-gestión; iv) Consulta con los pueblos indígenas involucrados antes de cualquier acción que pueda afectarles, directa o indirectamente. La consulta asegura que sus preocupaciones e intereses sean compatibles con los objetivos de la actividad o acción prevista; v) Reconocimiento formal de las instituciones tradicionales, sistemas internos de justicia y resolución de conflictos, y modos de organización sociopolítica; vi) Reconocimiento del derecho de los pueblos indígenas de definir y perseguir libremente su desarrollo económico, social y cultural

El principio de la autodeterminación puede ser implementado en la práctica a través de una variedad de mecanismos, incluyendo los siguientes: i) Disposiciones de autonomía; ii) Autogobierno; iii) Autogestión; iv) Control o influencia sobre ser- vicios básicos como la educación y la salud; iv) Reconocimiento y mantenimiento de los órganos tradicionales de toma de decisiones políticas y sistemas legales; v) Plena y efectiva participación en la vida pública. Estas disposiciones requieren que los estados y los pueblos indígenas acuerden términos apropiados, y cada vez más tales acuerdos negociados son la base para reconciliar las relaciones pasadas entre los Estados y los pueblos indígenas ${ }^{36}$.

\section{c) Derechos colectivos}

Los derechos indígenas toman principalmente su fuerza no desde una perspectiva de derechos individuales sino en cuanto derechos colectivos. Ello ha dado lugar a que algunas corrientes defiendan que los Estados constitucionales deban reconocer esos derechos colectivos como tales y protegerlos y garantizarlos, tanto mediante los textos constitucionales y en su desarrollo reglamentario, como también mediante la debida tutela judicial. La noción de derechos colectivos no es una cuestión pacífica por las dificultades que implica su titularidad, la complejidad de las acciones colectivas y otras cuestiones.

Los instrumentos internacionales básicos de derechos humanos protegen los derechos de los individuos y estableces obligaciones para los estados de garantizar, proteger y respetar dichos derechos. Los derechos relacionados con los pueblos indígenas buscan proteger, además de los derechos individuales, sus derechos colectivos, ya que el reconocimiento de tales derechos es necesario para asegurar la existencia, el desarrollo y el bienestar de los pueblos indígenas como colectividades distintivas. La experiencia ha demostrado que a menos que se respeten los derechos colectivos de los pueblos indígenas existe el riesgo de que tales culturas desaparezcan mediante la asimilación forzada. Por medio de declaraciones

\footnotetext{
${ }^{36}$ La Declaración de la ONU sobre los derechos de los pueblos indígenas llama a los Estados a consultar con los pueblos indígenas para obtener su consentimiento libre e informado previo a la aprobación de cualquier proyecto que afecte sus tierras y recursos. (Declaración de las Naciones Unidas sobre los derechos de los pueblos indígenas, Artículos 3, 4, 18, 19,23, 32).
} 
internacionales, y en algunos casos leyes y normas nacionales, todos los estados están comprometidos con la promoción de la diversidad cultural.

Los derechos colectivos de los pueblos indígenas incluyen el reconocimiento de sus historias, lenguas, identidades y culturas distintas, pero también de su derecho colectivo a las tierras, los territorios y los recursos naturales que tradicionalmente han ocupado y

usado, así como el derecho a su conocimiento tradicional, poseído colectivamente. Al crear y cumplir derechos colectivos para los pueblos indígenas, la comunidad internacional ha afirmado que tales derechos no deben entrar en conflicto con las normas internacionales de derechos humanos existentes sino complementarlas. Es decir, la implementación de los derechos humanos colectivos no debe afectar negativamente la implementación de los derechos individuales. Concretamente, abarcan: i) Participación plena y efectiva de los pueblos indígenas en cada etapa de cualquier acción que pueda afectarles directa o indirectamente. La participación de los pueblos indígenas puede ser a través de sus autoridades tradicionales o de una organización representativa. Esta participación también puede tomar la forma de co-gestión; ii) Consulta con los pueblos indígenas involucrados antes de cualquier acción que pueda afectarles, directa o indirectamente. La consulta asegura que sus preocupaciones e intereses sean compatibles con los objetivos de la actividad o acción prevista; iii) Reconocimiento formal de las instituciones tradicionales, sistemas internos de justicia y resolución de conflictos, y modos de organización sociopolítica; iii) Reconocimiento del derecho de los pueblos indígenas de definir y perseguir libremente su desarrollo económico, social y cultural.

\section{Multiculturalismo: análisis de diversas propuestas}

El multiculturalismo aparece como una propuesta de modelo jurídico- social, ante la crisis del proyecto monístico - universalista, que se ha mostrado ineficaz ante la evolución global y las diversas reivindicaciones de los más variados pueblos de diferentes culturas; es decir, un modelo jurídico distinto de los demás, que resguarda a las minorías que necesiten protección, de un Estado jerárquico, institucional, y que coaccionan a las culturas consideradas inferiores.

El multiculturalismo tiene una connotación positiva en la medida en que se remite a cuestiones como la convergencia y la convivencia de los más variados juicios de valores, costumbres de vida, actitudes, interpretaciones, visiones y especialmente culturas. El multiculturalismo tiene como uno de sus objetivos atender el clamor de los grupos sociales en desventaja con respecto a una ciudadanía diferenciada, permitiendo la constitución de sociedades más inclusivas ${ }^{37}$. El multiculturalismo ${ }^{38}$ no significa sólo una multiplicidad numérica de diferentes culturas sino un espacio colectivo que está instituido por grupos que se desarrollan a su ritmo, con sus mitos, ritos arqueológicos, en el respeto de los derechos humanos y como cultura idealizada justificada por los valores como parte importante de la conservación del universo y no como contrapeso de un planeta decadente, donde cabe prescindir del respeto a la cultura de minorías nacionales.

Debido a la dificultad de conceptualización y precisión de la temática, podemos decir que el multiculturalismo se convirtió en una manera de presentar las diferencias culturales en el mundo; sin embargo, siempre ha estado vinculado a concepciones emancipatorias y contra-hegemónicas, fundamentadas en acciones por el reconocimiento de la diferencia ${ }^{39}$.

\footnotetext{
${ }^{37}$ Sobre la ciudadanía en las sociedades multiculturales, vid. PÉREZ LUÑO, Antonio Enrique. "La ciudadanía en las sociedades multiculturales" en DE JULIOS CAMPUZANO, Alfonso (Editor) Ciudadanía y Derecho en la era de la globalización. Madrid, Dykinson, 2007, pp.261-288.

${ }^{38}$ DE SOUSA SANTOS, Boaventura. Por uma outra globalizaçāo: do pensamento único à consciência universal. 17ª ed. Rio de Janeiro: Editora Record, 2003, p. 26.

${ }^{39}$ DE SOUSA SANTOS, Boaventura. A Crítica da Razāo Indolente: contra o desperdício da Experiência. São Paulo: Cortez, 2003, p. 33.
} 
Con respecto a esta cuestión, Boaventura de Sousa Santos expone que las versiones emancipatorias del multiculturalismo se basan en el reconocimiento de la diferencia y del derecho a la diferencia y de la coexistencia ${ }^{40}$.

\subsection{La insuficiencia del liberalismo. La propuesta multiculturalista de Will Kymlicka}

El liberalismo occidental del pasado siglo no ha resultado muy acogedor para los derechos de los grupos diferenciados y de las minorías en la medida en que ha entendido que el reconocimiento universal de los derechos humanos los extendería, de per se, a todo los lugares. Ha confiado en que el marco del constitucionalismo de los Estados democráticos. Sin embargo, no ha sido así.

Actualmente, varios autores denuncian la insuficiencia del reconocimiento universal de los derechos y su protección constitucional para garantizar los derechos de grupos diferenciados. Así, Munck sostiene la insuficiencia del liberalismo clásico, y se refiere a los derechos de las minorías- como tales, porque el Estado parte de una lógica binaria Estado-individuo, que la aleja del reconocimiento de los derechos de las minorías como colectivo ${ }^{41}$.

La insuficiencia del liberalismo frente a los derechos de las minorías -advierte Soriano- se basa en los siguientes datos: a) la neutralidad del estado es un concepto insuficiente, que tendría que es sustituido por el concepto de cooperación estatal; y b) las minorías como colectivo exigen derechos (el derecho a la propia identidad sería el primero) no contemplados en la lógica liberal individualista que se basa en la autonomía del individuo y sus derechos. Efectivamente, ambos pilares del liberalismo -la neutralidad del Estado y la autonomía del individuo- no se acomodan a la defensa de los derechos de las minorías ${ }^{42}$.

Kymlicka trata de defender los derechos de las minorías dentro del marco del liberalismo. Expresamente sostiene: "he defendido el derecho de las minorías nacionales a mantenerse como sociedades culturalmente distintas, pero sólo si, y en la medida en que, estas minorías nacionales se gobiernen siguiendo los principios liberales". ${ }^{43}$

El liberalismo político de Rawls incorpora dos ideas que le hacen próximo al republicanismo: el bien común como objetivo de la política de la sociedad, un bien que es más valioso que los bienes particulares de los sujetos; y el concepto de virtud pública como virtud política de los ciudadanos -virtudes de la cooperación, de la civilidad, de la razonabilidad-44. Ambos conceptos acaban llevando a Rawls a un liberalismo democrático diferente del liberalismo clásico -el de la neutralidad del Estado y de los derechos formalesPero se trata de conceptos distintos a los que el comunitarismo sostiene, ya que la virtud comunitarista es la virtud privada de los bienes de vida. Entre los diversos comunitaristas defensores de los derechos de las culturas y de las minorías cabe destacar a Charles Taylor por haberse decantado claramente a favor de los derechos de las minorías frente al universalismo de los derechos del liberalismo.

Taylor contrapone la política del reconocimiento de la igualdad de las culturas a la política de la igualdad de los individuos. Para el liberalismo,

\footnotetext{
40 "Las versiones emancipadoras del multiculturalismo se basan en el reconocimiento de la diferencia y del derecho a la diferencia y de la coexistencia 0 construcción de una vida en común. Además de las diferencias de varios tipos, la idea de movimiento, de articulación de diferencias, de emergencia de configuraciones culturales basadas en contribuciones de experiencias y de historias distintas ha llevado a explorar las posibilidades emancipadoras del multiculturalismo, alimentando los debates e las iniciativas sobre nuevas definiciones de derecho, de identidad, de justicia y de ciudadanía". DE SOUSA SANTOS, Boaventura. A Crítica da Razāo Indolente: contra o desperdício da Experiência, cit., p. 33.

${ }^{41}$ DE MUNCK, J. "Les minorités en Europe", en LENOBLE, J. y DEWANDRE, N. (edts.) L'Europe au soir du siècle, Paris: Éditions Esprit, 1992, pp.137-161.

${ }^{42}$ SORIANO, Ramón. Los derechos de las minorías., cit., p.26.

${ }^{43}$ KYMLICKA, Will. Ciudadanía multicultural. Trad. De C. Castells, Barcelona: Paidós, 1995, p.213.

${ }^{44}$ RAWLS, John. El liberalismo político. Barcelona: Grijalvo Mondadori, 1997.
} 
todas las personas son iguales, de donde deriva que poseen la misma dignidad. La propuesta de Taylor es contradictoria con el liberalismo en la medida en que sostiene que la persona lo es en función de la cultura, previa a la misma persona, singular y diferenciada de otras culturas, de donde deriva el reconocimiento de la igualdad de las culturas. El igual reconocimiento de las culturas implica partir de la premisa de que todas las culturas son valiosas.

Taylor ataca el liberalismo individualista defendido según él por Dworkin y Rawls, partiendo de Kant, porque lo considera discriminatorio y demagogo. Advierte que la política de igual dignidad de las personas se convierte en discriminatoria porque desconoce el principio de la diferenciación cultural, colocando a todas las culturas al mismo nivel y siempre bajo la cultura dominante $e^{45}$. También critica el concepto de bien y de fines del liberalismo. El fin de la cultura es un fin colectivo y, en cambio, el fin del liberalismo es siempre un fin particular.

Iris Young se muestra crítica tanto con los comunitaristas, a los que critica su ideal de homogeneidad de la cultura excluyente como con el liberalismo, al que critica sus excesivos presupuestos generales, que acaban haciendo imposible una auténtica vida ciudadana. Al comunitarismo critica que la pretendida identidad de la comunidad derive en exclusión de los demás grupos que no reúnen las características ${ }^{46}$.

En relación a las comunidades indígenas, el reconocimiento de un grado significativo de auto- gobierno indígena requerirá, en numerosas ocasiones, establecer nuevas formas de participación y cooperación intergrupal entre el Estado y los pueblos indígenas que difícilmente podrían encontrar su lugar en un modelo de Estado-nación clásica, fundamentando en un idea de ciudadanía homogénea porque resulta incongruente con el reconocimiento de autoridad a los grupos intermedios. El pluralismo inherente al Estado multicultural debe traducirse en lo que Young denomina un modelo de ciudadanía diferenciada, que refleje el hecho de que los individuos tienen, por un lado, derechos individuales derivados de su condición general de ciudadanos (y más genéricamente, como seres humanos) y por otro, derechos derivados de su pertenencia a grupos identitarios diferenciados (en este caso, de su estatus o condición de miembros de una comunidad o pueblo indígena) ${ }^{47}$

En el debate acerca del multiculturalismo, para una mejor comprensión del tema, cabe destacar la distinción que Will Kymlicka hace entre Estados multinacionales. Apunta que una fuente de diversidad cultural es la coexistencia, dentro de un listado determinado, de más de una nación, donde nación significa una comunidad histórica, más o menos completa institucionalmente, que ocupa un territorio o una tierra natal determinada que comparte un lengua y una cultura diferenciada ${ }^{48}$. Las minorías nacionales, según Kymlicka, son grupos que fueron completamente formados y funcionan dentro de su tierra natal, pero que por alguna razón se incorporaron a otra sociedad ${ }^{49}$.

\footnotetext{
${ }^{45}$ TAYLOR, Charles. Multiculturalismo. La política del reconocimiento. México: Fondo de Cultura Económica, 2010.

${ }^{46}$ YOUNG, Iris Marion. Justice and the Politics of Difference. New Jersey, Princenton: Princenton University Press, 1990.

${ }^{47}$ TORBISCO CASALS, Neus, Derechos indígenas: reconocimiento y desafíos para la democracia constitucional y para los derechos humanos" en HIERRO, Liborio L (Coord.) Autonomía individual frente a autonomía colectiva. Derechos en conflicto. Madrid: Marcial Pons, 2014, pp.116-117.

${ }^{48}$ Y sigue apuntando que: "un país que contiene más de una nación no es, por lo tanto, una Nación-Estado, y sí un Estado multinacional, en el cual, las culturas menores forman las minorías nacionales" (traducción libre). KMLICKA, Will. Cidadania Multicultural. Una teoria liberal de los derechos de las minorías, cit., p. 26. Por su parte, Andréa Semprini, en relación a las minorías nacionales, apunta que una segunda interpretación del multiculturalismo privilegia su dimensión específicamente cultural. Concentra su atención sobre las reivindicaciones de grupos que no tienen necesariamente una base objetivamente étnica, política o nacional. Son movimientos sociales estructurados en torno a un sistema de valores comunes, de un estilo de vida homogéneo, de un sentimiento de identidad o pertenencia colectivo o incluso de una experiencia de marginación. Con frecuencia es este sentimiento de exclusión que lleva a los individuos a reconocerse, al contrario, como poseedores de valores comunes y a percibirse como un grupo aparte. SEMPRINI, Andréa. Multiculturalismo. Bauru: Edusc, 1999, p.44.

${ }^{49}$ GOMES LEITE, Rodrigo. Will Kymlicka: Possibilidades e limites de uma abordagem multicultural da Sociedade Civil. 2007, p. 5.
} 
Para Kymlicka, las culturas diferenciadas, que denomina como minorías nacionales, tienen el deseo de continuar siendo sociedades distintas de la cultura mayoritaria de la cual forman parte, exigen, por tanto, diversas formas de autonomía o autogobierno para garantizar su supervivencia como sociedades distintas ${ }^{50}$. La incorporación de diferentes naciones en un sólo Estado puede ser tanto de forma voluntaria, como cuando diferentes culturas se asocian y forman una federación para su mutuo beneficio ${ }^{51}$ como también involuntaria, como por ejemplo, la invasión y la conquista de una comunidad cultural por parte de otra, la cesión de una comunidad de una potencia imperial a otra, como cuando el suelo patrio es invadido por personas dispuestas a colonizar dicha comunidad. ${ }^{52}$

Muchas democracias occidentales son multinacionales, como por ejemplo, los Estados Unidos, en que existen diversas minorías nacionales, entre ellas podemos citar a los indios americanos, los portorriqueños, los descendentes de los mejicanos, todos estos se incorporaron involuntariamente en los Estados Unidos mediante conquistas y colonizaciones ${ }^{53}$. De hecho, muchos países del mundo son multinacionales en el sentido que sus fronteras se trazaron de forma que incluyeron el territorio ocupado por culturas preexistentes que generalmente disponían de autogobierno. Este es el caso de la mayoría de los países del antiguo bloque comunista ${ }^{54}$. Y prosigue afirmando que:

"[..] que estos países son Estados multinacionales no significa negar que, para ciertos fines, los ciu- dadanos se auto-consideren un único pueblo. Por ejemplo, los suizos tienen un resistente sentido de lealtad común, a pesar de sus divisiones culturales y lingüísticas. De hecho, los Estados multinacionales no pueden sobrevivir a menos que sus diversos grupos nacionales mantengan su lealtad con la comunidad política más amplia en la cual están integrados y con la cual cohabitan" ${ }^{\prime 55}$.

En cuanto a los Estados poliétnicos, Kymlicka considera que representan la segunda fuente de pluralismo cultural, de forma que un país sólo manifestará su pluralismo aceptando inmigrantes; es decir, acoger a un gran número de individuos y familias de otras culturas, permitiéndoles mantener algunos de sus costumbres y particularidades étnicas. ${ }^{56}$

Antes de la década de los años 60' se esperaba que los inmigrantes abandonaran su herencia distintiva y si asimilaran totalmente a las culturas existentes en el país para el cual inmigraron. Por consiguiente, se negaba la entrada en el país de algunos grupos considerados no asimilables, como por ejemplo, las restricciones de la inmigración china en Canadá y en Estados Unidos, o la política de inmigración de sólo blancos en Australia. La asimilación era considerada de fundamental importancia para el equilibrio político, algo que se racionaliza posteriormente mediante la difamación etnocéntrica de otras culturas ${ }^{57}$.

Al comienzo de los años 70', se redujo la presión ejercida en los grupos inmigrantes, y las naciones fueron abdicando el modelo de asimilación integracionista y adoptaron una política más comprensiva, tolerante y pluralista, incentivando

\footnotetext{
${ }^{50}$ KMLICKA, Will. Ciudadanía Multicultural. Una teoría liberal de los derechos de las minorías, cit., p. 25.

${ }^{51}$ Ibidem, p. 26.

${ }^{52}$ Ibidem, p. 26.

${ }^{53}$ Kymlicka apunta que: "Otras muchas democracias occidentales son también multinacionales, ya sea porque incorporaron por la fuerza a las poblaciones indígenas, (como, por ejemplo, Finlandia y Nueva Zelanda), o porque se constituyeron mediante federación, más o menos voluntaria, de dos o más culturas europeas (como por ejemplo, Bélgica y Suiza)". KMLICKA, Will. Ciudadanía Multicultural. Una teoría liberal de los derechos de las minorías, cit., pp. 26-27.

${ }^{54}$ Ibidem, p. 29.

55 Ibidem, p. 29.

${ }^{56}$ Ibidem, p. 29

${ }^{57}$ KMLICKA, Will. Ciudadanii Multicultural. Una teoría liberal de los derechos de las minorías. Trad. de Carmen Castells Auleda. Cubierta de Victor Viano. Barcelona: Ediciones Paidós Ibérica S.A., 1995, cit., pp. 29-30.
} 
que los inmigrantes mantuvieran diversos aspectos de su herencia étnica. Actualmente se acepta (aunque no unánimemente) que los inmigrantes tengan libertad para mantener algunos de su antiguas costumbres, dejando de ser estereotipados como antipatrióticos por mantener sus herencias culturales ${ }^{58}$.

Hay que distinguir la diversidad cultural de los inmigrantes y de las minorías nacionales. Los inmigrantes no son nacionales y no ocupan tierras natales, su especificidad se manifiesta esencialmente en su convivencia familiar, en las asociaciones voluntarias, algo que no se muestra contradictorio con su integración institucional ${ }^{59}$. A su vez, los colonizadores no eran considerado inmigrantes, ya que, no aspiraban a integrarse en otra cultura sino que intentaban reproducir su sociedad original en un nuevo territorio, con el objetivo de crear una sociedad institucionalmente completa que es una de las características esenciales de la colonización, algo bien distinto de la inmigración individual ${ }^{60}$.

Kymlicka apunta que obviamente, un único país puede ser tanto multinacional (como resultado de la colonización, de la conquista y confederación de comunidades nacionales) como poliétnico (como resultado de la inmigración individual familiar) ${ }^{61}$, citando como ejemplo Canadá y Estados Unidos que son Estados multinacionales y poliétnicos al mismo tiempo ${ }^{62}$, e incluso una "federación" como Brasil y Alemania. Concluye afirmando que prácticamente todas las democracias liberales son multinacionales o poliétnicas ${ }^{63}$.

En todas las democracias liberales, uno de los principales mecanismos usados para acomodar las diferencias culturales es la protección de los derechos civiles y políticos de los individuos, ${ }^{64}$ el respeto y la libre determinación y la soberanía de las minorías regionales.

Para ello, Kymlicka propone el reconocimiento de tres tipos de derechos designados para garantizar la protección de las minorías nacionales y su inclusión en la sociedad. El primero es el derecho de autogobierno, aunque las naciones que componen los estados multinacionales reivindiquen un tipo de autonomía política o de jurisdicción territorial para garantizar la plena y libre manifestación de su cultura y los intereses de su gente. ${ }^{65}$ En segundo lugar, tenemos los derechos poliétnicos, que según Kymlicka tienen como objetivo: "[...] ayudar a los grupos étnicos y a las minorías religiosas a expresar sus particularidades y su orgullo cultural sin que ello sea un obstáculo para su éxito en las instituciones económicas y políticas de la sociedad dominante" 66 , respetando la libertad de expresión conforme a su costumbres. En tercer y último lugar, Kymlicka aborda los derechos especiales de representación. Estos derechos garantizan la participación de las minorías étnicas y raciales, incluyendo a sus miembros en

\footnotetext{
${ }^{58}$ Ibidem, p. 30.

59 Ibidem, p. 31.

${ }^{60}$ Ibidem, p. 31-32.

${ }^{61}$ Idem, p. 34.

${ }^{62}$ KMLICKA, Will. Cidadania Multicultural. Una teoría liberal de los derechos de las minorías, cit., pp.31-34.

${ }_{63}$ "Prácticamente todas las democracias liberales son multinacionales o poliétnicas, o ambas de una sólo vez. El desafío del multiculturalismo consiste, por lo tanto, en acomodar las diferencias nacionales y étnicas de una manera estable y moralmente defendible (traducción libre)". KMLICKA, Will. Ciudadania Multicultural. Una teoría liberal de los derechos de las minorías, cit., p. 46.

${ }^{64}$ KMLICKA, Will. Ibidem.

${ }^{65}$ El derecho de autogobierno está reconocido en la Carta de las Naciones Unidas, en la parte en que trata el derecho a la autodeterminación de los pueblos. Sin embargo, uno de los principales problemas encontrados es que en las Naciones Unidas aún no ha habido un acuerdo con respecto a la definición de lo que son los pueblos, puesto que este derecho ha sido aplicado sólo a las colonias de ultramar (tesis del agua salada) y no a las minorías nacionales internas. Muchas minorías nacionales insisten en que también son pueblos o naciones y que también tienen el derecho de autodeterminarse vía referéndum y plebiscito democráticamente. KMLICKA, Will. Ciudadanía Multicultural. Una teoría liberal de los derechos de las minorías, cit., pp. 47-48.

${ }^{66}$ [...] tienen como objetivo ayudar a los grupos étnicos y las minorías religiosas a que expresen su particularidad y su orgullo cultural sin que ello obstaculice su éxito en las instituciones económicas y políticas de la sociedad dominante. KMLICKA, Will. Ciudadanía Multicultural. Una teoría liberal de los derechos de las minorías, cit., p. 53.
} 
este proceso político ${ }^{67}$, a través de la conciencia social en una red virtual social democrática ligada a los Derechos Humanos. Estos tres derechos tienen la intención de contribuir a la modificación de la coyuntura actual de injusticias y desigualdades en las que la sociedad está inmersa; son derechos idealizados con el objetivo de proteger la diversidad cultural del mundo como derecho legítimo universal independientemente del carácter de su pueblo.

Liberalismo y comunitarismo no parecen ser las mejores teorías para acoger los derechos diferenciados. Ni existen Estados verdaderamente liberales ni tampoco todas las culturas son homogéneas. El imperialismo jurídico (o monismo jurídico) es el que hasta hace poco se erigía como modelo único en la historia de las relaciones entre las culturas, es decir, la imposición por la fuerza de la cultura dominante. Pero tampoco las opciones del universalismo de Rawls, del aldeanismo de Taylor y del interculturalismo leve de Kylimcka parecen ser las opciones puras que puedan admitirse. En nuestra opinión, un interculturalismo fuerte, basado en el respeto y en la prudencia de las culturas, apoyado en un diálogo intercultural, podría presentarse como la mejor opción ${ }^{68}$.

\subsection{El Multiculturalismo y los Pueblos Indígenas}

La evolución de los pueblos indígenas está estrechamente vinculada con el proceso de colonización, con las misiones catequistas y civilizadoras, con el proceso de descolonización y con el desarrollo del principio de autodeterminación de los pueblos.
En la caracterización de la modernidad, del siglo XIX, desde una óptica europea, el hombre occidental ha sido relacionado con lo racional, lo activo, lo dominante, lo individualizado y diferenciado, frente al hombre indígena que se proyectaba como lo irracional, lo pasivo, lo dominado, lo gregario. Sin embargo, sus manifestaciones culturales y sociales, su universo simbólico y organizativo no puede llevarnos a negar que detrás cada creación cultural y tras cada manifestación social de los pueblos indígenas no hay individuos concretos ${ }^{69}$.

La civilización occidental se basa en la individualidad y en el derecho de propiedad, garantía de la libertad liberal. El liberalismo dio entrada a programas jurídicos destinados a asimilar lo diferente para hacerle extensible los derechos propios del proceso de generalización e incluso, de universalización de los derechos. Sin embargo, esto no funciona con quienes no encajan en este esquema. Los indígenas no han sido reconocidos desde el paradigma liberal como estrictamente ciudadanos, como sujetos de pleno derecho. Durante décadas, constitucionalmente ni han sido mencionados. El indígena no existía jurídicamente, se niega su subjetividad, en un doble sentido: tanto en su consideración de sujetos individuales ${ }^{70}$ como en cuanto pueblos. Y cuando el Derecho ha empezado a tomarlos en consideración, ha sido en cuanto comunidades que debían de ser asimilados, uniformizados y, sino, al menos tutelados. Los ordenamientos jurídicos, las Constituciones del XIX y el Derecho Internacional han invisibilizado y silenciado a los indígenas, lo que les ha llevado a ser los excluidos de la ciudadanía, apartados del espacio público y seres desposeídos de derechos ${ }^{71}$.

\footnotetext{
${ }^{67}$ Ibidem.

${ }^{68}$ Nos adherimos así a la propuesta de R. Soriano en relación a lo que denomina la "cuarta vía", la del interculturalismo. SORIANO, Ramón. Los derechos de las minorías, cit., pp.48-49.

${ }^{69}$ OLIVA MARTÍNEZ, Daniel J. "La deformación antropológica y su repercusión en el reconocimiento de los derechos humanos a los indígenas" en PECESBARBA MARTÍNEZ, Gregorio et at. (Editores) Historia de los Derechos Fundamentales (siglo XIX), Madrid: Dykinson, 2009, pp.575-576. Sobre la formación del individualismo en la modernidad, vid. DE JULIOS CAMPUZANO, Alfonso. "Individualismo y modernidad. Una lectura alternativa" en Anuario de Filosofía del Derecho, Tomo XII, Madrid: Nueva época, 1995, pp.239-269.

${ }^{70}$ Resulta dificil encontrar referencias a indígenas concretos, excepto caciques de algunos pueblos con actuaciones relevantes. La historia de los indígenas es la historia de los diversos pueblos.

${ }^{71}$ OLIVA MARTÍNEZ, Daniel J. "La deformación antropológica y su repercusión en el reconocimiento de los derechos humanos a los indígenas", cit., pp.605-606.
} 
La evolución posterior que condujo a un indigenismo, tampoco fue la solución en la medida en que los "blancos" eran quienes dictaban las normas para "regularizar" a los indígenas. El indigenismo intentó incorporar a los indígenas como ciudadanos, desarraigándoles de su medio físico y de su cultura, pero los resultados no fueron los esperados sino que empeoraron en algunos casos en la medida en que fomentaron que las tierras les fueran arrebatadas. Despreciando la diversidad, se implantaron programas homogeneizadores en lo social, lo político, lo lingüístico, lo cultural, de privatización de sus tierras comunales. Estas medidas se aplicaron desde justificaciones ideológicas y postulados filosóficos propios de la cultura occidental, basada en la propiedad privada, en los derechos humanos individuales y la generalización de la ciudadanía, que no podía dar buenos resultados en un contexto tan diferente. La extensión de los derechos individuales conllevaba que los indígenas tuvieran que "desindianizarse". El liberalismo asimilacionista y monocultural ha sentado las bases para la reivindicación de un Estado pluricultural y unas reivindicaciones sustentadas en los derechos colectivos. Es decir, refleja una especie de interpretación "a la contra" de los derechos individuales e insiste en la defensa de los derechos colectivos indígenas ${ }^{72}$. Todo ello ha acabado acentuando el reduccionismo comunitarista por parte de los pueblos indígenas, como una forma de defender y proteger más adecuadamente sus derechos colectivos.

Uno de los primeros documentos internacionales relacionado con el tema es el ya citado Convenio no 107 de la Organización Internacional del Trabajo, adoptada en 1957, relativa a la protección y a la integración de las poblaciones indígenas y de otras poblaciones tribales o semitribales en los países independientes. En este Convenio, subyacen las ideas de uniformidad jurídica y de asimilación como mejor forma de abolir las desigualdades y promover el "avance" de las culturas indígenas. Tal ideario influyó en organismos como el Banco Mundial, cuya política para estas poblaciones era la implementación de proyectos de desarrollo progresivo para permitir la aculturación "lenta y gradual".73

La demanda indígena sobre el derecho a la diferencia y a la autodeterminación cuestiona la centralidad en la producción de normas y de imposición de un patrón cultural. Estas demandas, que determinan nuevas probabilidades de protección jurídica han contribuido a la deconstrucción de la visión unificadora y homogénea de las identidades nacionales. Las ciencias humanas han determinado la necesidad de un diálogo intercultural que permita la convivencia con respecto a las diferencias; en este sentido, el concepto de identidad nacional, que se considera como cuerpo único, es una edificación ideológica. ${ }^{74}$

Para los indios, la dominación es una violación de las garantías constitucionales sobre su territorio y su autodeterminación. Los indios sostienen el derecho a ocupar y aprovechar plenamente los recursos naturales de estas áreas, ya que antes de representar una Unidad de Conservación son tierras indígenas. Basan su demanda en el derecho originario, que es precedente y superior a cualquier otro que eventualmente pueda haberse formado y en la obligación del Estado para garantizar su propiedad efectiva. ${ }^{75}$

El reconocimiento de los diferentes derechos indígenas, por parte de los actores estatales y no estatales, implica una preocupación más allá de los derechos fundamentados en el principio de igualdad entre los individuos y la no discrimi-

\footnotetext{
72 OLIVA MARTÍNEZ, Daniel J. "La deformación antropológica y su repercusión en el reconocimiento de los derechos humanos a los indígenas", cit., p. 623.

${ }^{73}$ ROULAND, Norbert. Direito das minorías e dos povos autóctones. Brasília: Editora UnB, 2004.

${ }^{74}$ CALEFFI, P. "O que é ser indio hoje?" En: SIDEKUM, Antônio (Org.). Alteridade e multiculturalismo. Unijuí: ljuí, 2003.

${ }^{75}$ BESSA ANTUNES, Paulo. Direito Ambiental. 5ำ ed., ampl. e atual., Rio de Janeiro: Lumen Juris, 2001.
} 
nación. Los derechos de los pueblos indígenas se fundamentan en el derecho a la autodeterminación de los pueblos -contemplada en los Pactos Internacionales de los Derechos Humanos de 1966-, lo que conlleva discusiones sobre las probables interpretaciones de criterios de referencialidad del concepto "pueblos" y de la forma de ejercicio de esta autodeterminación. En el caso de la tierra Raposa Serra do Sol, como en otros casos, se polarizan las acciones y los objetivos de los pueblos indígenas en conflicto con la "soberanía estatal" y con la "uniformidad constitucional", soportando discursos dicotómicos y míticos de Justicia y Orden. ${ }^{76}$

La probabilidad de autodeterminarse significa garantizar que los pueblos indígenas no necesitan ser determinados por otros que no sean ellos mismos. No precisan de la tutela estatal como pueblos e individuos. Para Sousa Santos, ${ }^{77}$ "el Derecho a la autodeterminación fue limitado a los pueblos subyugados por el colonialismo europeo." Ejemplo peculiar fue la sumisión impuesta por los conquistadores a los pueblos indígenas.

Los movimientos indígenas han discutido en varios países el reconocimiento de un derecho que regule la vida social indígena, usado como un medio para resistir a un orden normativo que no reconoce la diversidad y que penaliza las prácticas que la componen. Sus exigencias se regulan sobre la idea de que el derecho estatal es una pieza-clave en la disolución de las particularidades culturales de los pueblos minoritarios, sirviendo como un instrumento de dominación cultural. Estas denuncias de opresión y de des- precio tratan de reconfigurar las relaciones entre los pueblos indígenas y el Estado, siendo parte de una gran plataforma de demandas que incluyen el reconocimiento constitucional de la existencia de los pueblos indígenas, la garantía de sus tierras, el derecho al desarrollo cultural, económico y social y el reconocimiento de niveles significativos de autonomía. ${ }^{78}$

Actualmente en la mayoría de los países están presentes diversas culturas, por lo tanto, cada vez son más multiculturales y, al mismo tiempo, más permeables ${ }^{79}$. Kymlicka sostiene que, según estimaciones recientes, los 184 Estados independientes del mundo contienen más de 600 grupos de lenguas vivas y 5.000 grupos étnicos, en una sociedad plural.

Entre estos diferentes grupos existentes están incluidos diversos grupos indígenas. Eso quiere decir que nuestros valores, nuestros principios y nuestras creencias, son una referencia más en un mundo marcado por la diversidad ${ }^{80}$. Kymlicka clasifica la heterogeneidad de pueblos dentro de un mismo país, a modo de un Estado multinacional y, como ya hemos indicado, un país que contenga más de una nación no es una nación-Estado, y sí un Estado multinacional, compuesto por diversas culturas menores denominadas minorías nacionales. ${ }^{81}$ Dentro de los Estados multinacionales, los pueblos indígenas integran las Ilamadas minorías nacionales, que son grupos que fueron completamente formados y funcionan dentro de su tierra natal, pero que por alguna razón fueron incorporados a la otra sociedad ${ }^{82}$, diferenciados en el saber tradicional.

\footnotetext{
${ }^{76}$ BLOCH, Anne-Christine. "Minorities and Indigenous Peoples" En Eide, A. (Org.) Economic, Social and Cultural Rights, A Textbook. Netherlands: Martinus Nijhoff Publishers, 1995.

${ }^{77}$ DE SOUSA SANTOS, Boaventura. “Una concepción multicultural de los derechos humanos". Revista Memoria. Bogotá, n. 101, 1997, p. 47

${ }^{78}$ TTURRALDE, Diego A. "Reclamo e reconocimiento del derecho indígena en América Latina: logros, límites y perspectivas." Revista del Instituto Interamericano de Derechos Humanos, vol. 41, 2005: 17-47.

${ }^{79}$ TAYLOR, Charles. Multiculturalismo. Lisboa: Instituto Piaget, 1997, p. 83.

${ }^{80}$ DE SOUSA SANTOS, Boaventura. "Por uma concepçāo multicultural de direitos humanos". En: DE SOUSA SANTOS, Boaventura (org.). Reconhecer para libertar: os caminhos do cosmopolitismo multicultural. Rio de Janeiro: Civilização Brasileira, 2003, p. 4 (Série Reinventar a emancipação social: para novos manifestos, v. 3).

${ }^{81}$ KMLICKA, Will. Cidadania Multicultural. Una teoria liberal de los derechos de las minorías, cit., p. 26.

82 LEITE, Rodrigo Gomes. WILL KYMLICKA: Possibilidades e limites de uma abordagem multicultural da sociedade civil. VI Conferência Regional de ISTR para América Latina y el Caribe. Salvador Bahia, Brasil. Organizan: ISTR y CIAGS/UFBA, 2007, p. 5.
} 
La lucha multicultural está arraigada en el proceso histórico de desarrollo de los países, que comenzaron por un proceso de conquista y coIonización, acompañado de una política de asimilación forzada y de eliminación de la identidad de los pueblos que habitaban el territorio de estos países mucho antes de la llegada de los conquistadores. ${ }^{83}$

Los pueblos indígenas forman parte de este proceso histórico de conquistas y colonización. Después la eliminación de gran parte de su población y segregación de su cultura, empiezan a renacer con la conciencia y el deseo del reconocimiento de sus derechos y respeto como minorías nacionales. ${ }^{84}$

Para una mejor comprensión de la necesidad del reconocimiento y protección de las diferencias formadoras de las sociedades indígenas, conviene prestar atención al concepto de grupos indígenas. Según Diegues, los grupos indígenas se diferencian culturalmente, son grupos humanos diferenciados bajo el punto de vista cultural y que reproducen históricamente su modo de vida, de forma más o menos separada, en función de la cooperación social y las propias relaciones con la naturaleza ${ }^{85}$. La antropóloga Carneiro da Cunha, subraya que las comunidades indígenas son las comunidades que se consideran segmentos dis- tintos de la sociedad nacional en virtud de una conciencia de su continuidad histórica con las sociedades precolombinas. ${ }^{86}$

De estas conceptualizaciones cabe deducir que una de las principales características de los pueblos indígenas es la necesidad de su autodeterminación, debido a las particularidades y distinciones de su cultura y costumbres, junto con el deseo y la obligación de mantenimiento y manifestación de estas; lo cual lleva a pensar que el multiculturalismo es una ocasión para la búsqueda del reconocimiento y el respeto de las diferencias que integran la vida de estos indígenas.

Las comunidades indígenas se han ido enfrentando a las diversas dificultades en los últimos tiempos de forma que la búsqueda de su identidad, afirmación y reconocimiento de sus derechos se convierte en una batalla constante, en la búsqueda de un mundo que respete la diferencia. Durante muchos años se aseguró que sólo el hombre blanco era normal y superior con respecto a las demás personas, mientras que los indios eran considerados humanos inferiores por no corresponder al estereotipo o a los patrones culturalmente impuestos y aceptados por la mayoría de la sociedad dominante. Aílton Krenak ${ }^{87}$ apunta que el multiculturalismo surge para cues-

\footnotetext{
83 TAYLOR, Charles. Multiculturalismo. Lisboa: Instituto Piaget, 1997, p. 46.

84 "Diferentes grupos humanos habitan el territorio nacional, originando diversas configuraciones socioculturales. Insertados en este contexto están los pueblos indígenas que desde hace mucho tiempo han vivido numerosos conflictos, donde se observa de manera general que la violencia y la intolerancia han imperado. Ante este cuadro, las respuestas de estos pueblos ha sido la constante búsqueda del respeto y la necesidad de negociación de la convivencia con la diferencia". MARÉS DE SOUZA FILHO, Carlos Frederico y STEFANES PACHECO, Rosely Aparecida. Dignidade da pessoa humana, saberes tradicionais e sustentabilidade indígena - desafios e possibilidades. Curitiba: Juruá, 2008, p. 3499.

85 "Grupos humanos diferenciados bajo el punto de vista cultural, que reproducen históricamente su modo de vida, de forma más o menos separada, según la cooperación social y las propias relaciones con la naturaleza. [...] que han desarrollado modos particulares de existencia [...". DIEGUES, Antônio Carlos S. O mito moderno da natureza intocada. São Paulo, Brasil, Hucitec, 2001, p. 27. López Bárcenas también describe las comunidades indígenas, apuntando que son las que forman una unidad social, económica y cultural, asentadas en un territorio y que reconocen autoridades propias de acuerdo con sus usos y costumbres. LOPES BARCENAS, Francisco. "Los sistemas indígenas de cargos en la Mixteca," en A. Hernández Nuñez y F. López Bárcenas (eds.), La fuerza de la costumbre: Sistema de cargos en la Mixteca oaxaqueña, México, Centro de Orientación y Asesoría a Pueblos Indígenas,2002, p. 57 (Derechos Indígenas, vol. 8).

${ }^{86}$ CARNEIRO DA CUNHA, Manuela. "Definiçoes de Índio e Comunidades Indígenas". En: SANTOS, Sílvio Coelho (Org.). Sociedades Indígenas e o Direito: uma questão de Direitos Humanos. Florianópolis: UFSC, 1985, p. 35. En cuanto a la definición de pueblos indígenas, Rodrigo Gomes Leite apunta al modo de vida: "Los pueblos indígenas son definidos como pueblos que tradicionalmente vivían de sus tierras pero fueron colonizados por conquistadores que les forzaron a integrarse en una economía y cultura extrañas a su modo de vida. Mientras las naciones subestatales ambicionaban a la construcción de un Estado con economía e instituciones políticas, muchas veces formalmente idénticas con el resto de la sociedad, los pueblos indígenas claman por el derecho de mantener su cultura y su creencia tradicionales y para participar dentro de sus propias condiciones del mundo moderno". GOMES LEITE, Rodrigo Gomes. WILL KYMLICKA: Possibilidades e limites de uma abordagem multicultural da sociedade civil, cit., p. 6; también, vid. BERRAONDO, M. (Coord.) Pueblos indígenas y derechos humanos, Bilbao, Universidad de Deutso, 2006.
}

87 ".... las relaciones fueron siempre muy desiguales y apoyadas en una visión del mundo muy exclusiva sobre lo que es el ser humano. Sostiene que casi todos los grupos humanos tienden a darse cuenta que se consideran determinados otros grupos como personas de menor valor con respecto a ellos mismos". KRENAK, Ailton. "O eterno retorno do encontro". En: Adauto Novaes (org.), A outra margem do Ocidente. Sâo Paulo: MINC-Funarte/Companhia das Letras, 2001, p. 73. 
tionar esta jerarquización del ser humano, proponiendo el respeto a las diferencias de los pueblos indígenas y demás minorías. ${ }^{88}$

Imponer a los indios que sean iguales al resto de la sociedad dominante, partiendo de una visión integracionista y asimilacionista, es una forma de descaracterizar a este pueblo. Garantizar el derecho de ser diferente es lo que llevan reivindicando de los pueblos indígenas. Sobre el derecho a la diferencia, algunos autores sostienen que los indios gozan del derecho de ser diferentes, lo que no significa la existencia de una inferioridad de derechos, al contrario, explica que a los indígenas no pueden ser negados los derechos deferidos a los ciudadanos ${ }^{89}$, y la naturaleza y la tierra son sus vidas.

La idea central del multiculturalismo no es sólo propiciar derechos isonómicos entre las minorías y los que integran la cultura dominante o garantizar los derechos del individuo indio en sí. El objetivo es el reconocimiento público de derechos diferenciados de los grupos indígenas como un todo. El Derecho de cada una de las naciones indígenas, indisolublemente ligado a las prácticas culturales, es el resultado de una convivencia aceptada y profesada por todos los integrantes ${ }^{90}$.

En la actualidad, con la asistencia de la comunidad internacional, ha habido un progreso en el reconocimiento de los derechos de los pueblos indígenas en el mundo en el ámbito nacional e internacional. La presencia cada vez más visible y acentuada de liderazgos indígenas en el panorama político nacional e internacional, prueban la fuerza de estos pueblos y sus aspiraciones por el hecho de que conservan sus tradiciones, costumbres y todas sus prácticas culturales, en un mundo cada vez más globalizado. ${ }^{91}$

En relación a Brasil, el debate sobre multiculturalismo y derechos se encuentra aún en un estado bastante incipiente. Los trabajos más antiguos sobre el tema, desde el derecho, datan de finales de los años 90, habiéndose intensificado en los últimos años. Esto tal vez se deba al interés que, en el medio académico, se ha despertado por el incremento de políticas públicas de inclusión social y, en consecuencia, por la judicialización de muchas políticas públicas, conllevando a que tales temas sean discutidos en los tribunales brasileros. Esto se dio, por ejemplo, con la cuestión de las cuotas raciales en las universidades públicas federales, cuando la Ley 12.711/2012 estableció la política de cuotas mesuradas por el criterio del color en las Universidades en una amplia -por lo demás inédita- affirmative action, que afecta a todas Universidades públicas federales. La medida suscitó un gran debate en Brasil, con algunos antropólogos tomando posición, con base en la teoría de la miscegenación, en contra del hecho de que la pseudo identidad racial sea la base de la construcción de una identidad jurídica.

Otro ejemplo es el del juicio promulgado por el Supremo Tribunal Federal de la Petición 3.388, promovida por dos senadores del Estado de

\footnotetext{
${ }^{88}$ De Souza Santos apunta que: "[...] la hermenéutica diatópica presupone la aceptación del siguiente imperativo transcultural: tenemos el derecho de ser iguales cuando la diferencia no nos hace sentir inferiores; tenemos el derecho de ser diferentes cuando la igualdad no nos descaracterize". DE SOUSA SANTOS, Boaventura. Reconhecer para Libertar: os caminhos do cosmopolitismo multicultural. Rio de Janeiro: Civilizaçāo Brasileira, 2003 , p. 458.

${ }^{89}$ LEMOS DOS SANTOS FILHO, Roberto. "Índios, Convenção 169/OIT e Meio Ambiente". Revista CEJ (Brasília), v. 33, p. 16-21, 2006, p. 19.

90 "El Derecho de cada nación indígena, indisolublemente ligado a las prácticas culturales, es el resultado de una convivencia aceptada y profesada por todos los integrantes. Al contrario de eso, el Derecho estatal es fruto de una sociedad profundamente dividida, donde la dominación de unos por los otros es el primado principal y el individualismo, lo que marca el rasgo característico. La distancia que media del Derecho indígena al del Estado es la misma que media del colectivismo al individualismo. De ahí deriva otra diferencia fundamental: el Derecho de cada nación indígena es estable, porque nacido de una praxis de un acuerdo social, no conoce instancia de modificación formal y se modifica en la propia praxis; sin embargo, el Derecho estatal, a partir del Poder Legislativo como instancia formal de modificación, está en constante alteración". SOUZA FILHO, Carlos Frederico Marés de. O Renascer dos Povos Indígenas para o Direito, cit., p. 74.

91 "En cuanto seamos nosotros quienes decidamos por ellos, continuarán siendo objeto de la historia que otros hacen. La verdadera liberación del indio es reconocerlos como sujeto, en cuyas manos está su propio destino; sujeto capaz de juzgarnos según sus propios valores, como nosotros los hemos siempre juzgado; sujeto capaz de ejercer su libertad sin restricciones, como nosotros exigimos ejercerla. Ser sujeto pleno es ser autónomo. El problema indígena sólo tiene una solución definitiva: el reconocimiento de la autonomía de los pueblos indígenas". WOLKMER, Antônio Carlos. Pluralismo Jurídico. Fundamentos de uma nova cultura no Direito, cit., p. 385.
} 
Roraima en contra de la demarcación de las tierras indígenas conocidas como "Raposa Serra do Sol"92. También aquí surgieron argumentos multiculturalistas hasta entonces inéditos en la jurisprudencia del STF ${ }^{93}$. Al norte del Brasil, en la frontera con Guyana y Venezuela, viven desde tiempos inmemoriales los indios Ingaricó, Mucaxi y Wapixana. En el 2005, dos senadores del Estado de Roraima recurrieron al Poder judicial para impugnar el modelo continuo de demarcación de tierras Raposa Serra do Sol, argumentando la existencia de vicios formales en la Portería de demarcación, así como que el Estado de Roraima sufriría, adicionalmente, grandes perjuicios económicos con la adopción de tal modelo de demarcación, ya que muchos no indios explotaban actividades comerciales en aquellas tierras (sobre todo cultivo de arroz). Se alegó también que la demarcación de las tierras, con la consecuencia de que estas pasan a ser de la Unión, mutilaría el Estado de Roraima, perturbando el "concepto federativo"94.

En la decisión, proferida en 2009, el Supremo Tribunal Federal decidió a favor de mantener la demarcación anterior y llamó la atención sobre importantes temas ligados a la situación jurídica del indio del Brasil. Uno de estos aspectos fue precisamente la comprensión de aquello que se entiende por "indio", incorporando en esta categoría no sólo los silvícolas, tal como las Constituciones republicanas anteriores a la del 88, sino también los indios en proceso de aculturación. El Supremo Tribunal Federal decidió que la Constitución Federal, al utilizar el sustantivo indios, siempre en plural, vino a expresar la diferenciación de los aborígenes por numerosas etnias, revelando un claro propósito constitucional de retratar una diversidad indígena tanto "interétnica" como "in- traétnica". Más allá de esto, el STF reconoce que los indios, a pesar del proceso de aculturación, permanecen como indios con el fin de protección constitucional. De esta forma la categoría "indios", para el tribunal, es no solo expresión de un aspecto de la diversidad cultural en el Brasil, como es, ella también, plural.

El tema del multiculturalismo despunta en el contexto de la sentencia del caso Raposa Serra do Sol en la medida en que se aborda la tensión entre el derecho a la igualdad y los derechos de los indios. Inspirado por aquello que Ilama "Constitucionalismo Solidario o Fraternal", el Ministro Ayres Brito, relator de la causa, promueve una conciliación del principio de igualdad con el derecho a una especial protección de las minorías. En este punto, el relator elige una vía intermedia en la polémica entre los liberales y los comunitaristas, o sea, entre los que acogen el universalismo de los derechos y los adeptos de un cierto relativismo cultural. Se trata de una solución, en las palabras del Relator, incorporada a la decisión, "de un periodo constitucional que se vuelca hacia el hacer efectivo un nuevo tipo de igualdad: la igualdad civil - moral de minorías, teniendo en cuenta el proto-valor de la integración comunitaria".

En este contexto argumentativo, de inéditos contornos en el STF, Ayres Brito introduce incluso elementos típicamente pos-colonialistas, al referirse a una "época constitucional compensatoria de desventajas históricamente acumuladas, que ha de hacerse viable por mecanismos oficiales de acciones afirmativas". De esta forma se pretende asegurar a los indios "el derecho de disfrutar de un espacio agrario que les asegure medios dignos de subsistencia económica para poder más

\footnotetext{
92 Informe de Admisibilidad No. 125/10, Petición 250/04 - Pueblos Indígenas de Raposa Serra do Sol (Brasil), 23 de octubre de 2010.Disponible en: http:// www.oas.org/es/cidh/indigenas/decisiones/cidh.asp (Acceso el 30-12-2014).

${ }^{93}$ NEUENSCHWANDER MAGALHAES, Juliana. "Los límites del multiculturalismo en las sociedades multiculturales: formas de inclusión y exclusión" en Fórum. Historiae luris. Disponible en: ‘ http://www.forhistiur.de/fr/2014-08-neuenschwander-magalhaes/> (Acceso el 02-04-2015).

${ }^{94}$ Nos adherimos a las valoraciones y significado de este caso realizadas por J. NEUENSCHWANDER MAGALHAES "Los límites del multiculturalismo en las sociedades multiculturales: formas de inclusión y exclusión" en Fórum. Historiae luris. Disponible en: ‘http://www.forhistiur.de/fr/2014-08-neuenschwander-magalhaes/s (Acceso el 02-04-2015).
} 
eficazmente preservar su identidad somática, lingüística y cultural". Esta conciliación permite incluso una visión del proceso de "aculturación" que no consistiría necesariamente en pérdida de la identidad étnica, pero sí en un "sumatorio de visiones de mundo": "una suma y no una sustracción. Ganancia y no pérdida. Relaciones interétnicas de provecho mutuo, para caracterizar ganancias culturales incesantemente acumulativas. Concretización constitucional del valor de la inclusión comunitaria por la vía de la identidad étnica" (Ayres Brito, voto en la PE 3388).

Aunque con fundamento en el Ilamado "constitucionalismo solidario" y "fraternal", el STF reconoce la importancia del indio en el contexto nacional brasileño, pero refuta la utilización de expresiones como "pueblo", "nación" y "territorios" indígenas. De esta forma, a pesar del reconocimiento de un pluralismo cultural, con base en la diversidad de usos, costumbres, tradiciones de diversas etnias indígenas, el STF excluye de plano la perspectiva de un Estado multinacional, según por ejemplo el modelo de aquello que pretende Bolivia. Excluye también la posibilidad de un reconocimiento del pluralismo jurídico propiamente dicho, puesto que afirma que, en tierras indígenas, vale exclusivamente el derecho nacional.

Lejos de construir una unidad política, curiosamente el STF asume, para sí, el significado que tiene la tierra para los indios: tierra indígena, en el imaginario colectivo aborigen, no es un simple objeto de derecho, sino que gana la dimensión de verdadero ente o ser que resume en sí a toda ancestralidad, toda coetaneidad y toda posterioridad de una etnia. Donde la prohibición constitucional de sacar a los indios de las tierras tradicionalmente ocupadas por ellos, así como el reconocimiento del derecho a una posesión permanente y usufructo exclusivo, paralelamente con la regla de que todas esas tierras "son in- alienables e indisponibles, y los derechos sobre ellas, imprescriptibles" (§ 4으 del art. 231 de la Constitución Federal).

\section{3. ¿Un giro decolonial de la ciudadanía indígena? Hacia un pluralismo jurídico}

La valoración del procedimiento de descolonización en América Latina ha sido polémica y no podemos externos en un análisis de la misma. Sin embargo, como estamos analizando la ciudadanía de los pueblos indígenas, no podemos dejar de hacernos eco de las últimas propuestas al respecto. El debate entre quienes sostienen que la línea seguida por el proceso de descoIonización no ha sido adecuada y reclaman un giro decolonial $y$, aquellas otras corrientes que sí consideran que los postulados de los que se partió en la modernidad eran los acertados. Este planteamiento no puede ser entendido en sus justos términos sin el pluralismo jurídico.

\section{1. ¿Giro decolonial de la ciudadanía indígena?}

El sentido de injusticia histórica sufrida por los pueblos indígenas a causa de la colonización está expresada en la Resolución aprobada por la Asamblea General [sin remisión previa a una Comisión Principal (A/61/L67 y Add.1)] por la que se aprueba la Declaración 61/295 de las Naciones Unidas sobre los derechos de los pueblos indígenas, el 3 de septiembre de 2007:

"preocupada por el hecho de que los pueblos indígenas han sufrido injusticias históricas como resultado, entre otras cosas, de la colonización y de haber sido desposeídos de sus tierras, territorios y recursos, lo que les ha impedido ejercer, en particular, su derecho al desarrollo de conformidad con sus propias necesidades e intereses ${ }^{\prime \prime 95}$.

\footnotetext{
${ }^{95}$ Resolución aprobada por la Asamblea General [sin remisión previa a una Comisión Principal (A/61/L67 y Add.1)] por la que se aprueba la Declaración de las Naciones Unidas sobre los derechos de los pueblos indígenas, el 3 de septiembre de 2007, Anexo, p.2. Disponible en: ‘ http://www.un.org/esa/socdev/ unpfii/documents/DRIPS_es.pdf. (Acceso el 30-12-2014).
} 
La expansión geopolítica de grandes imperios multinacionales, así como la colonización europea inaugurada desde el siglo XV en América Latina, fueron procesos que abonaron a la emergencia del pluralismo jurídico, cuyo común denominador fue la imposición del derecho del colonizador a los pueblos o naciones sometidas. Como señala Bartolomé Clavero, en la época colonial, si bien las comunidades indígenas conservaron sus "usos y costumbres", estos no lograron florecer de manera autónoma, ya que finalmente el derecho colonial se impuso sobre la vida individual y colectiva de los indígenas ${ }^{96}$.

Esta misma jerarquía normativa sobrevivirá tras la descolonización política en los siglos XIX y XX, en el contexto de los emergentes Estados independientes en Asia, África o América Latina, donde el derecho del colonizador será asumido y declarado oficial al lado de otras concepciones jurídicas concurrentes. $^{97}$ De hecho, tras varios siglos de dominación y segregación etnocultural que supuso la colonización europea, muchas de las expresiones jurídicas extraestatales continuaron en la práctica cotidiana al margen del derecho oficial, resistiendo procesos de asimilación e integración que caracterizó la construcción del Estado nacional en nombre de una concepción monista, la misma que redujo la diversidad cultural preexistente a una sola visión dominante del derecho, la cultura, la nación, la religión, la lengua, etc. ${ }^{98}$ De ese modo, la diversidad de prácticas jurídicas vivas en con- textos locales fueron abstraídas o eliminadas por la lógica del Derecho estatal empeñada en reproducir el sistema jurídico moderno occidental sustentado en la trilogía Estado/soberanía/derecho. Por eso dirá -con razón- Boaventura de Sousa Santos $^{99}$, que "la concepción modernista del derecho llevó a una gran pérdida de experiencia y práctica jurídica y, de hecho, legitimó un "juridicidio" masivo, esto es, la destrucción de prácticas y concepciones jurídicas que no se ajustaban al canon jurídico modernista".

La colonialidad es un elemento complementario de la descolonización. La categoría giro decolonial100 implica, al parecer, un tránsito que va de la crítica contra la llamada colonialidad del saber, a la transformación afirmativa de diferentes espacios, subjetividades individuales y colectivas, instituciones y modos de ser que generan y perpetúan relaciones de dominación. ${ }^{101}$ La decolonialidad también se manifiesta en la subversión de los universalismos abstractos que se producen desde las entrañas de la modernidad/colonialidad, los cuales funcionaban y funcionan como plataforma de fundamentación del gobierno de la diferencia, a partir de enunciados como la salvación, la civilización, el progreso, el desarrollo y la democracia. De ahí parte la propuesta de la consecución de un universalismo concreto asociado con la articulación participativa de la diferencia. Se defiende una pluriversalidad antes que la universalidad. Implica un ejercicio afirmativo

\footnotetext{
${ }^{96}$ CLAVERO, Bartolomé. Geografía jurídica de América latina. Pueblos indígenas entre constituciones mestizas, México, Siglo XXI, 2008; también, vid. STAVENHAGEN, Rodolfo. Clases, colonialismo y aculturación, Guatemala, Ministerio de Educación, 1968.

${ }^{97}$ Sobre ciudadanía indígena, pluralismo y giro decolonial, vid. GARZÓN LÓPEZ, Pedro. Ciudadanía indígena. Del multiculturalismo a la colonialidad del poder. Prólogo de J.Mํ. Sauca Cano. Madrid: Centro de Estudios Políticos y Constitucionales, 2001.

${ }^{98}$ VILLORO, Luis. Estado plural, pluralidad de culturas, Paidós, México D.F., 1998.

${ }_{99}$ DE SOUSA SANTOS, Boaventura. Sociología jurídica crítica. Para un nuevo sentido común en el derecho, cit, p.47; también, vid. CABEDO MALLOL, Víctor. Pluralismo jurídico y pueblos indígenas, Barcelona: Icaria, 2012.

${ }^{100}$ La noción de "giro descolonial" hizo su aparición en los primeros años del siglo XXI en universidades norteamericanas y latinoamericanas como parte del conjunto de debates e investigaciones sobre la naturaleza de la modernidad y de la colonialidad. Entre sus principales características se destaca el hecho de que la misma organiza una explicación de los experiencias actuales asumiendo que el fin formal de las colonias a escala global no tiene un correlato en la desarticulación de las formas de dominación coloniales en los estados nación poscoloniales, en particular y en las relaciones globales, norte-sur, en general. Por el contrario, la idea es que se produjo una transición del colonialismo moderno a la colonialidad global, lo cual transformó las prácticas de poder clásicas pero no alteró la relación centro periferia. Vid. CASTRO-GÓMEZ, Santiago y GROSFOGUEL, Ramón (Eds.) Nómadas (Col), núm. 27, Universidad Central Bogotá, Colombia, octubre, 2007. Disponible en: ‘http://www.ceapedi.com.ar/imagenes/biblioteca/libros/147.pdf. (Acceso el 22.03.2016). También, como uno de los formuladores del giro des-colonial, vid. QUIJANO, Aníbal. 2000. "Colonialidad del poder y clasificación social". Journal of World System Research, Volumen 11, № 2. 342-386.

${ }^{101}$ Algunos de sus principales autores son Walter Mignolo, Aníbal Quijano, Ramón Grosfoguel y otros, que también se apoyan en las elaboraciones de Enrique Dussel y Frantz Fanon.
} 
basado en el reconocimiento de la otredad. ${ }^{102}$ Esa colonialidad del poder, del saber y del ser adquiere un especial protagonismo cuando se aplica a los pueblos indígenas. Implica un ejercicio de insurgencia epistémica que conlleva repensar el mundo indígena desde sus propias coordenadas epistémicas, reivindicando sus propios saberes que durante años han estado marginalizados o invisibilizados por las luces de la modernidad.

Ello se ha tenido su reflejo en el derecho indígena, del que sólo se ha reconocido su juridicidad cuando ha sido convalidado por el derecho oficial de base individualista y monista. Mientras tanto, se considera usos y costumbres o fenómenos infra-jurídicos. Se lamentan de que el filtro sigue siendo el mismo, partiendo del dualismo correcto/incorrecto, legal/ilegal, racional/irracional. ${ }^{103}$ Se sostiene que mientas "no se cuestione la matriz del poder colonial, difícilmente las demandas indígenas pueden ser satisfechas simplemente con políticas de reconocimiento oficial, cuando las barreras estructurales y sistémicas son mucho más complejas y profundas". 104

Sin embargo, este planteamiento del giro decoIonial también cuenta con detractores que consideran que la principal propuesta del giro decoIonial consiste en rechazar la "modernidad", pues representa la "colonialidad del poder" que se constituyó a partir de la conquista y colonización de América. ${ }^{105}$ Renuncia a pelear por la emancipación social y desprecia cualquier propuesta universal de lucha para los explotados y oprimi- dos, pues esto equivale a reproducir un nuevo meta-relato "totalitario" propio de la modernidad, de la cual son partícipes por igual el cristianismo, liberalismo y el marxismo, a los que consideran como los tres principales micro-relatos. Critican el materialismo histórico y su perspectiva de lucha de clases. En el plano programático, su orientación radica en "descolonizar" el conocimiento, por lo cual caracteriza como grandes avances a los gobiernos populistas de la región, en particular a Evo Morales en Bolivia y el chavismo en Venezuela, por desarrollar una nueva "plataforma epistémica" en América Latina. ${ }^{106}$

\subsection{El pluralismo jurídico}

Pluralismo jurídico, iusdiversidad e interlegalidad son tres de los conceptos que actualmente definen mejor la existencia y diálogo entre diversas esferas de racionalidad y de sistemas jurídicos. En las relaciones de las comunidades indígenas y los Estados en los que se insertan, se superponen estos sistemas, causando disfunciones.

El primer término, el "pluralismo jurídico" no es un concepto unívoco y, por tanto, está abierto tanto al universo del derecho como a otras ciencias sociales. Si se interpreta en el sentido más amplio posible, cabe entenderlo como el fenómeno da coexistencia de más de un sistema jurídico que funcione de manera legítima, excaz y paralela en una única base territorial, tanto con el posicionamiento por parte del Estado que reconozca sólo como derecho la normativa que provenga de sus

\footnotetext{
102 DUSSEL, Enrique. Hacia una filosofía política crítica, Bilbao: Desclée de Brouwer, 2001.

${ }^{103}$ GARZÓN LÓPEZ, Pedro. Ciudadanía indígena. Del multiculturalismo a la colonialidad del poder. Prólogo de J.Mª Sauca Cano. Madrid: Centro de Estudios Políticos y Constitucionales, 2001, p.291.

${ }^{104}$ GARZÓN LÓPEZ, Pedro. Ciudadanía indígena. Del multiculturalismo a la colonialidad del poder, cit., p.294.

${ }^{105}$ ARTAVIA, Víctor. Crítica al giro decolonial: entre el anticomunismo y el populismo reformista. Disponible en: « https://www.mas.org.ar/?p=5474). (Acceso el 21.03.2016).

${ }^{106}$ Podría considerarse que el giro decolonial se inscribe en la lógica del Foro Social Mundial (FSM) y su propuesta de "otro mundo es posible", combinando rasgos reformistas y anti-comunistas. "Para los decolonialistas el desarrollo histórico se comprende desde la "colonialidad", la cual "consiste en develar la lógica encubierta que impone el control, la dominación y la explotación, una lógica oculta tras el discurso de la salvación, el progreso, la modernización y el bien común" Está se encuentra relacionada con la modernidad, la cual asocian orgánicamente con el proceso histórico mediante el cual Europa se constituyó como región hegemónica, por lo cual sostienen una peculiar conclusión: ino se puede ser moderno sin ser colonial! Producto de la dialéctica "modernidad/colonialidad" aducen que se configuró una "matriz colonial del poder", clave estratégica para comprender las relaciones políticas mundiales instauradas por Europa desde la conquista de América en el siglo XVI, lo cual explica el "componente colonial de la modernidad" (MIGNOLO, Walter. La idea de América Latina. La herida colonial y la opción decolonial. Gedisa. Barcelona, España: 2007). El "capitalismo eurocentrado" y su "matriz colonial de poder" es la definición determinante, estableciéndose casi que una línea directa entre la conquista española y las guerras mundiales del siglo XX.
} 
mecanismos o×ciales de producción, en una línea eminentemente positivista, o bien, aquél que acoja en su seno como válido otro modelo de derecho, a pesar de que derive de otras fuentes de autoridad ${ }^{107}$.

De Sousa Santos advierte que la pluralidad jurídica infraestatal -no vamos a referirnos a la supraestatal- no sólo no es un residuo de los tiempos premodernos de los países que aún no han completado el proceso de "modernización" sino que es constitutiva del carácter desigual, dispar y excluyente de dicho proceso, y por eso está destinada a ser reinventada y reproducida recurrentemente a medida que se despliega la "modernización"108.

\section{Como acertadamente ha destacado Garzón} López, el pluralismo es un concepto complejo y polisémico que describe la coexistencia de varios sistemas jurídicos en un mismo espacio sociopolítico, siendo el derecho estatal uno más de los derechos existentes en la realidad social ${ }^{109}$. El desafío principal del pluralismo jurídico cuestiona la exclusividad de la teoría del monismo jurídico para explicar fenómenos jurídicos contemporáneos, ya que sostiene que la realidad rebasa sus marcos explicativos ante la emergencia de diferentes actores colectivos cuyas normas de autorregulación no se reducen al derecho estatal ni se explican desde la ciencia jurídica tradicional. Entre las diversas manifestaciones de este plura- lismo cabe destacar el representado por los pueblos indígenas ${ }^{110}$; las favelas en Brasil ${ }^{111}$; los nuevos movimientos sociales ${ }^{112}$; la lex mercatoria ${ }^{113}$. Si bien la voz "pluralismo jurídico" se entiende mejor al contrastarla con la perspectiva monista que defiende un sólo derecho soberano e indivisible, jerarquizado y centralizado en la figura del Estado; el uso lingüístico del pluralismo, sin embargo, sigue siendo una locución ambigua y polisémica, que puede prestarse a diferentes interpretaciones y formulaciones.

Una característica de quienes defienden el tipo de pluralismo jurídico de signo monista, por lo general, es que asumen una postura estatalista del derecho, legitiman el monopolio jurídico estatal desde la ciencia jurídica tradicional; otorgan poca relevancia a otras fuentes autónomas de producción normativa que no sea la derivada de la ciencia positivista del derecho; $y$, en consecuencia, suelen relativizar el concepto de pluralismo jurídico en sentido estricto o de tipo sociológico.

El segundo término, la "iusdiversidad", ha sido acuñado por Carlos Frederico Marés de Souza Filho, especialista en derecho indígena, en sus escritos jurídicos. Con esta fórmula pone de manifiesto el fenómeno de la coexistencia de más de un sistema de derecho en vigor dentro de un mismo territorio, pero aquel que admite y opera como un sistema paralelo de derecho construido a través de la costumbre, según las creencias y tradiciones

\footnotetext{
${ }^{107}$ DAMAS DA SILVEIRA, Edson. "Jusdiversidade e interlegalidade indígena na experiência amazônica" en Carlos Frederico Marés de Souza Filho, Heline Sivini Ferreira e Caroline Barbosa Contente Nogueira (Organizadores), Direito socioambiental: uma questāo para América Latina, Curitiba, Letra da Lei, 2014, pp.99-108; Sobre el pluralismo, vid. las obras del especialista como el professor Wolkmer: WOLKMER, Antonio Carlos y CORREAS, Oscar. Crítica Jurídica na América Latina. Augascalientes/Florianópolis, UFRSC-Mispat, 2013; también, WOLKMER, Antonio Carlos. "Pluralismo juridico, movimentos sociais e processos de lutas desde America Latina" en WOLKMER, A.C.; FERNANDEZ M. LIXA, I. (Orgs.) Constitucionalismo, Descolonización y pluralismo jurídico en América Latina, NEPE - Universidad Federal de Santa Catarina (UFSC) Aguascalientes / Florianópolis, 2015, pp. 95-103.

${ }^{108}$ DE SOUSA SANTOS, Boaventura. Sociología jurídica crítica. Para un nuevo sentido común en el derecho. Madrid-Bogotá, Editorial Trotta/ILSA, 2009, p.386. ${ }^{109}$ GARZÓN LÓPEZ, Pedro. "Pluralismo” en Eunomia. Revista en Cultura de la Legalidad, no5, septiembre 2013-febrero 2014 pp.186-193. Disponible en: http:// eunomia.tirant.com/?p=2245 (Acceso el 26-12-2014).

${ }^{110}$ Vid. CORREAS, Oscar. Derecho indigena mexicano I, UNAM, Ediciones Coyoacán, México, D.F., 2007; YRIGOYEN, Raquel. Pautas de coordinación entre el derecho indígena y el derecho estatal, Fundación Myrna Mack, Guatemala, 1999; CLAVERO, Bartolomé. Derecho Indígena y Derecho Constitucional en América, Siglo XXI, México, D.F., 1994.

${ }^{111}$ DE SOUSA SANTOS, Boaventura. Sociología jurídica crítica. Para un nuevo sentido común en el derecho, Trotta-ILSA, Madrid-Bogotá, 2009.

${ }_{112}$ WOLKMER, Antonio Carlos. Pluralismo Jurídico. Fundamentos para una nueva cultura jurídica, Mad, Sevilla, 2000.

113 DE SOUSA SANTOS, Boaventura. La globalización del Derecho. Los nuevos caminos de regulación y la emancipación, Universidad Nacional de Colombia - ILSA, Bogotá, 1998; también, vid. OLGIATI, V., "El nuevo pluralismo jurídico y la lex mercatoria en la dinámica constitucional europea”, en SILVA J.A. (coord.), Estudios sobre lex mercatoria. Una realidad internacional, UNAM, México D.F., 2006.
} 
de los pueblos indígenas, sin resquicios de intervención del Estado mediante la imposición de sus valores y formalidades. Se pregunta: “¿Qué hacer con aquellas sociedades (las "otras") que viven al margen del Estado y de la Constitución, representadas especialmente por los pueblos indígenas?"114 Para Marés, el que algunos Estados latino-americanos hayan incluido en sus Constituciones el reconocimiento de una sociedad plúriétnica (Paraguay, Colombia y, hasta cierto punto, Brasil), no es suficiente. El simple hecho de adoptar para estos pueblos el sistema jurídico occidental, imaginado como un conjunto de valores universales, no garantiza una convivencia pacífica y armónica, sino solamente un retorno al concepto de integración. Los principios universales de reconocimiento integral de los valores de cada pueblo solamente pueden ser formulados como libertad de acción según sus propias leyes, lo que significa haber reconocido el derecho a su jurisdicción. Es lo que Marés denomina iusdiversidad. ${ }^{115}$

El tercer término es el de "interlegalidad", en la línea de los trabajos de Boaventura de Souza Santos. Aquí el centro de atención se dirige al fenómeno de la relación, es decir, al sentido de la heterointegración observada entre los dos sistemas de derecho, uno construido e impuesto por el Estado y al que se le podrá denominar " "jurisdicción estatal”, y aquel otro tradicionalmente mantenido, resistido y operado por los pueblos indígenas en el seno de sus propias comunidades, designado como "jurisdicción indígena". Así, cabe entender por "interlegalidades" los esfuerzos de descripción y de que se adscriben al encuentro de esos dos sistemas de derecho considera- dos como válidas sus hipótesis de interrelacionamientos y repercusiones en el ámbito interno de cada uno de los ordenamientos normativos analizados. Generalmente, por razones prácticas, el interés se concentra más en la reacción del Estado nacional, procurando entender los discursos y de qué manera la jurisdicción estatal recibe o niega a jurisdicción indígena.

De Sousa Santos destaca que lo que verdaderamente es nuevo en la cuestión indígena es el surgimiento de una coalición transformadora, transnacional, compuesta por ONG indígenas y no indígenas y que han estado Ilamando la atención de la opinión pública sobre las violaciones de los derechos históricos de los indígenas y presionando, tanto a organizaciones internacionales como a los propios Estados nacionales para que condenen las violaciones y adopten las medidas activas para empezar a corregir la injusticia histórica masiva. Es un esfuerzo transnacional, que desborda los límites estatales y, por tanto, el pluralismo jurídico infraestatal, del que habíamos partido ${ }^{116}$.

En los últimos años sí se ha podido apreciar un cierto progreso en la relación o×cial con los pueblos indígenas, relativizándose el principio del monopolio de derecho por parte do Estado nacional, incluso promovido por representantes de la sociedad no india. Esto significa que la propia sociedad que acoge, ha ido reconociendo que existen sistemas de derechos diversos y paralelos al del Estado Brasileño, igualmente legítimos, con el fin de regular comportamientos de segmentos sociales especí×cos, y válidos para la resolución de conlictos dentro de las respectivas comunidades afectadas ${ }^{117}$.

\footnotetext{
114 MARÉS DE SOUZA FILHO, Carlos Frederico. Os Direitos Humanos e os povos indígenas. Disponible en: http://www.dhnet.org.br/direitos/sos/indios/mares. html (Acceso el 26-12-2014). Sobre este tema el autor publicó un extenso artículo titulado "La universalidad parcial de los derechos humanos" en la serie documentos de ILSA, Bogotá. También está inserto en su libro: "O renascer dos povos indígenas para o direito", Curitiba: Juruá, 1998.

115 MARÉS DE SOUZA FILHO, Carlos Frederico. Os Direitos Humanos e os povos indígenas, cit.

${ }^{116}$ DE SOUSA SANTOS, Boaventura. Sociología jurídica crítica. Para un nuevo sentido común en el derecho, cit., p.387.

117 Por ejemplo, casos en los que si el procesado ya había recibido una condena por parte de la comunidad indígena, por el delito cometido, se aplicaba el principio de que no se podía juzgar por segunda vez y no se le procesaba, lo cual refleja un respeto por la aceptación de la jurisdicción indígena. Es el caso del proceso de homicidio llevado a cabo por el indígena Basílio, en el Tribunal de Jurado de la Justicia Federal de Roraima, el día 31 de mayo do ano de 2000, cuando por votación unánime se absolvió al reo porque ya había sido juzgado y condenado anteriormente por la asamblea general de su propia comunidad, siéndole aplicada la pena de destierro por 10 años, destitución de todos sus partencias y alejamiento forzado de sus familiares por igual plazo. (DAMAS DA SILVEIRA, Edson. “Jusdiversidade e interlegalidade indígena na experiência amazônica”, cit., pp.105-106).
} 
En algunas comunidades, son los propios indígenas quienes realizan servicios de vigilancia para reprimir y controlar el tráfico de drogas, consumo de bebidas alcohólicas y otras conductas. Se trata de movimientos organizados por los indígenas dentro das sus aldeas, todo registrado mediante la producción de documentos escritos y en la línea de actuaciones de las autoridades del Estado nacional. De hecho, algunas decisiones judiciales de primera instancia están respetando la jurisdicción indígena, aunque siempre teniendo como límite el respeto a la Declaración universal de derechos humanos y a los derechos fundamentales prescritos en la Constitución Federal de 1988.

Ello no debe hacer pensar que se trata de movimiento articulado de los representantes del Estado nacional encaminado a establecer unas pautas hermenéuticas para la aceptación de esa especie de "heterointegración tolerada", sino que se continúa resolviendo los procesos caso por caso, muy dependientes todavía de la disposición y buena voluntad de cada uno de los actores jurídicos implicados en el proceso.

Hay que reconocer la cotidianeidad de una tradición jurídica que convive con una cultura política, marcada por una democracia excluyente, por un sistema representativo clientelista, por formas de participación elitista y por experiencias de pluralismo limitado. ${ }^{118}$ Como recuerda Howard J. Wiarda, los documentos y los textos legales elaborados en América Latina, en gran parte, han sido la expresión de la voluntad y del interés de sectores de las elites dominantes, formadas e influenciadas por la cultura europea o anglo-norteamericana. Pocas veces, en la historia de la región, las constituciones y los códigos positivos reproducen, rigurosamente, las necesidades de todos los segmentos de la sociedad civil. En general, los textos legales "(...) fueron formulados y promulgados de arriba para abajo. Fueron concebidos por las elites, y no por los trabajadores. Difícilmente los documentos jurídicos pueden ser considerados neutros, equilibrados y apolíticos (....."119

Como subraya Wolkmer, el proceso de independencia de América Latina y la ruptura con España y Portugal, generaron las condiciones para el surgimiento de una elite local, que incorporó y difundió los principios de una tradición jurídica, marcada por el idealismo abstracto iusnaturalista, por el formalismo dogmático-positivista y por la retórica liberal-individualista. Naturalmente, la formación de esa cultura jurídica latino-americana está apoyada en un pasado económico colonial-extractivista y a la construcción posterior de un sistema socio-político elitista, individualista y deshumanizador ${ }^{120}$.

A diferencia del pluralismo jurídico europeo, un rasgo distintivo del pluralismo jurídico latinoamericano es que tiene su origen en la praxis del movimiento alternativista presente en países como Argentina, Colombia, México, Ecuador, Perú, etc., aunque el movimiento más importante se remonta al contexto brasileño, siendo sus precursores el llamado "movimiento de los jueces gauchos", quienes rompieron con la tradición formalista del positivismo jurídico, al impulsar un uso alternativo del derecho a favor de los sectores más desprotegidos ${ }^{121}$.

El punto de partida de los alternativistas se halla en la acusación de la crisis del paradigma del monismo jurídico, y a la ineficacia del positivismo y formalismo jurídico para dar cuenta de las distintas lógicas de autorregulación extra-estatal formuladas por los nuevos sujetos emergentes, dejando el Estado de ser la única fuente de pro-

\footnotetext{
${ }^{118} 1983$ WIARDA, Howard J. Op. cit, pp. 85-86.

119 WIARDA, Howard J. Op. cit, p. 113.

${ }^{120}$ WOLKMER, Antonio Carlos. "El humanismo en la tradición de la cultura jurídica Latino-Americana". Disponible en la World Wide Web: ‘http://bibliotecavirtual.clacso.org.ar/ar/libros/derecho/wolk1.rtf ). (Acceso el 26-12-2014). También, del mismo autor, vid. (Org.). Direito e justiça na América Indígena: da conquista à colonizaçāo. Porto Alegre: Livraria do Advogado, 1998; História do direito no Brasil. 3ª . ed. Rio de Janeiro, Forense, 2002.

${ }^{121}$ SOUZA, M.L, El uso alternativo del Derecho. Génesis y evolución en Italia, España y Brasil, Universidad Nacional de Colombia-ILSA: Bogotá, 2001.
} 
ducción y regulación jurídica ${ }^{122}$. Los contextos de opresión, de desigualdad y exclusión social caracterizada por la ausencia del Estado, constituyen muchas veces, fuentes de creación o recreación de la alternatividad jurídica, en la línea de satisfacer "necesidades humanas fundamentales"123. Este es el escenario donde se afianzan los nuevos actores sociales portadores del nuevo pluralismo jurídico, tales como las rondas campesinas, las favelas, el movimiento sin tierra de Brasil, las callampas en Chile, las ciudades perdidas en México, las villas miseria en Argentina, etc.

La estrategia más recurrente para producir distintas formas de alternatividad jurídica, a juicio de Wolkmer ${ }^{124}$, discurre por dos vías principales: i) prácticas legales institucionales de producción alternativa dentro del derecho oficial; y ii) prácticas o mecanismos jurídicos no institucionales fuera del sistema jurídico estatal. El primer caso consiste en procedimientos alternativos institucionalizados que potencialmente pueden ser utilizados, explotados y apropiados por los nuevos sujetos sociales para reivindicar derechos adquiridos y reconocidos por el derecho oficial, y que pueden a su vez ser: a) prácticas "reconocidas oficialmente" como la conciliación, la mediación, el arbitraje, los juzgados especiales o justicia de paz; y b) el uso alternativo del derecho, al forzar el marco formalista del derecho estatal hacia una interpretación judicial favorable a los sectores más pobres y oprimidos (hoy podría ser el garantismo). En cambio, el segundo supuesto rompe con el paradigma jurídico monista para dar cauce al derecho alternativo. A tales efectos se recurre a prácticas no institucionalizadas de producción jurídica y solución de conflictos paralelas al derecho estatal. Esta ha sido la experiencia de los nuevos movimientos sociales latinoamericanos que, con sus prácticas autogestionarias alternativas han fomentado una cultura jurídica pluralista, constitutiva del pluralismo jurídico.

Nos adherimos a la opinión de Garzón López en cuanto a que el derecho desarrollado por las corporaciones trasnacionales o las entidades subnacionales no siempre comporta una barrera infranqueable al derecho estatal ni sugiere el rechazo total de la gramática jurídica positivista, pues está previsto que una característica asociada al pluralismo jurídico es precisamente la interlegalidad, en cuanto que los sistemas jurídicos entran en diálogo y establecen diferentes puntos de contacto, de intercambio e imbricaciones en distintas esferas normativas ${ }^{125}$. Por tal razón, la interlegalidad es una experiencia presente en aquellos contextos de interacción entre el derecho estatal y el no estatal, lo que demuestra que los sistemas jurídicos no están cerrados a la "contaminación" de otras influencias normativas. Si bien esta "porosidad legal" presenta mayor influencia en el ámbito procedimental (juicios, testigos, pruebas, audiencias, resoluciones escritas, etc.); sin embargo, no parece modificar sustancialmente la concepción de justicia según el significado normativo y valorativo compartido en contextos locales o comunitarios ${ }^{126}$.

\section{A modo de conclusiones}

A pesar de los avances en materia indígena reconocidos en las diversas Constituciones de América Latina, las prácticas autoritarias y tutelares aún están vigentes en la política indigenista siendo irreconciliables o incluso dejando invisible el derecho diferenciado de los indígenas. Junto

\footnotetext{
122 SÁNCHEZ RUBIO, David. "Sobre el derecho alternativo. Absolutización del formalismo, despotismo de la ley y legitimidad", en DE LA TORRE RANGEL, J.A. (ed.), Derecho alternativo y crítica jurídica, México, D.F.: Porrúa, 2002.

${ }^{123}$ WOLKMER, Antonio Carlos. Pluralismo Jurídico. Fundamentos para una nueva cultura jurídica,cit, p.213.

${ }^{124}$ WOLKMER, Antonio Carlos. Pluralismo Jurídico. Fundamentos para una nueva cultura jurídica, cit,, pp.247-260.

${ }^{125}$ DE SOUSA SANTOS, Boaventura. Crítica de la razón indolente: contra el desperdicio de la experiencia: para un nuevo sentido común: La ciencia, el derecho y la política en la transición paradigmática, Bilbao: Desclée de Bruower, 2003, pp.250-253.

${ }^{126}$ GARZÓN LÓPEZ, Pedro. "Pluralismo", cit.
} 
a textos constitucionales modernos, en muchos casos perduran unas viciada y arcaicas normas preconstitucionales. Habría que impulsar las modificaciones necesarias (desarrollo de normativa postconstitucional, acomodación de normas preconstitucionales al texto constitucional) para que se reconozca el derecho diferenciado indígena.

Sigue existiendo una confusión entre si la política hacia los indios debe ser de asimilación, de tutela, de integración en la cultura del blanco civilizado. $\mathrm{Al}$ indio se le sigue considerando relativamente incapaz y la tendencia es la de "sacarle de su estado semi-salvaje y llevarle a la civilización".

El reconocimiento constitucional de la diversidad étnica del país, afirmando las culturas de los pueblos indígenas, sus tierras, tradiciones, organizaciones sociopolíticas, conllevan una conquista de autonomía dentro del propio Estado. Este reconocimiento no supone la construcción automática de una "nación", sino que intenta garantizar que en el ámbito territorial de los pueblos indígenas, por una cuestión de Derecho originario, sean ellos mismos los responsables de diseñar e implementar sus instituciones, organizaciones, normas, relaciones de poder político y económico, y las relaciones dialógicas con la sociedad de adscripción.

La educación puede ser el instrumento más eficaz, por una parte, para que los indios puedan entender sus derechos y defenderlos ante los tribunales con mayor eficacia. $Y$, a su vez, para que las comunidades "civilizadas" dominantes se interesen por arbitrar fórmulas consensuadas de convivencia. Los textos constitucionales reconocen esos derechos diferenciados y habrá que continuar trabajando en su implantación y consolidación. Para ello se hace necesaria una triple vía: por un lado, la promulgación de leyes infraconstitucionales que permitan concretar y desarrollar los derechos establecidos en las diversas cartas magnas de todos aquellos países en que se reconocen derechos a los pueblos indígenas; en segundo lugar, que las violaciones, vulneración, no reconocimiento de estos derechos se lleven a sede judicial, de manera que los tribunales puedan actuar de garantes de sus derechos; por último, los movimientos sociales indígenas pueden desarrollar un importante papel en orden a canalizar el imprescindible diálogo pluricultural que debe establecerse entre las autoridades, las comunidades, los intereses empresariales, la FUNAI y todos los demás organismos que participan en la defensa de los derechos de los pueblos indígenas.

\section{Bibliografía}

AA.W., Los Derechos de los pueblos indígenas y tribales en la práctica. Una guía sobre el Convenio núm. 169 de la OIT, http://www.llo.org/wcmsp5/groups/public/---ed_norm/---normes/documents/publication/wcms_113014.pdf (Acceso el 15.04.2014).

ARTAVIA, Víctor. Crítica al giro decolonial: entre el anticomunismo y el populismo reformista. Disponible en: ‘ https://www.mas.org.ar/?p=5474). (Acceso el 21.03.2016).

BARBARA OOMEN, Group "Rights in Post-Apartheid South Africa: The Case of the Traditional Leaders" En Journal of Legal Pluralism and Unofficial Law, n. 44, 1999, pp. 73-103.

BELLOSO MARTíN, Nuria. "Los derechos de los pueblos indígenas como derechos emergentes", en GORZEVSKI, Clovis (Organizador), Direitos Humanos e participacâo politica. Vol. V, Porto Alegre, (Brasil), Imprensalivre, 2014, pp. 59-110.

BerRaOndo, M. (Coord.) Pueblos indígenas y derechos humanos, Bilbao, Universidad de Deusto, 2006.

BESSA ANTUNES, Paulo. Direito Ambiental. 5a ed., ampl. e atual., Rio de Janeiro: Lumen Juris, 2001.

BLOCH, Anne-Christine. "Minorities and Indigenous Peoples" En Eide, A. (Org.) Economic, Social and Cultural Rights, A Textbook. Netherlands: Martinus Nijhoff Publishers, 1995.

CABEDO MALLOL, Víctor. Pluralismo jurídico y pueblos indígenas, Barcelona: Icaria, 2012.

CALEFFI, P. "O que é ser indio hoje?" En: SIDEKUM, Antônio (Org.). Alteridade e multiculturalismo. Unijuí: Ijuí, 2003.

CARNEIRO DA CUNHA, Manuela. "Definiçōes de Índio e Comunidades Indígenas". En: SANTOS, Sílvio Coelho (Org.). Sociedades Indígenas e o Direito: uma questão de Direitos Humanos. Florianópolis: UFSC, 1985. 
CASTRO CID, Benito de, "La universalidad de los Derechos humanos: ¿Dogma o mito?" en Derechos y Libertades, no5, Universidad Carlos III de Madrid-BOE, 1995, pp.

CELSO, D. A. M. Direitos humanos e conflitos armados. Rio de Janeiro: Renovar, 1997.

CLAVERO, Bartolomé. Geografía jurídica de América latina. Pueblos indígenas entre constituciones mestizas, México, Siglo XXl, 2008.

CLAVERO, Bartolomé. "Estado plurinacional: aproximación a un nuevo paradigma constitucional latinoamericano". En ROJAS, Rafael (Ed.) De Cádiz al Siglo XXI: doscientos años de constitucionalismo en Hispanoamérica. México: Taurus-Centro de Investigación y Docencia Económicas, 2012.

CASTRO-GÓMEZ, Santiago y GROSFOGUEL, Ramón (Eds.) Nómadas (Col), núm. 27, Universidad Central Bogotá, Colombia, octubre, 2007. Disponible en: ‘ http://www.ceapedi.com.ar/imagenes/biblioteca/libros/147.pdfi. (Acceso el 22.03.2016).

CORREAS, Oscar, (Coordinador), Derecho Indígena Mexicano I, Coyoacán México, CEIICH-NAM/CONACYT/Ediciones, 2007.

COSTA, Sérgio; WERLE, Denílson Luís. "Reconhecer as diferenças: liberais, comunitários e as relações raciais no Brasil". En SCHERER WARREN, llse et al. Cidadania e multiculturalismo: a teoria social no Brasil contemporâneo. Lisboa: Editora da UFSC e Socius, 2000, p. 82-116.

CUNHA, C. "A noção de direito costumeiro e os direitos indígenas na Nova Constituição do Brasil". América Indígena XLIX (2), 1989.

DE JULIOS CAMPUZANO, Alfonso. "Individualismo y modernidad. Una lectura alternativa" en Anuario de Filosofía del Derecho, Tomo XII, Madrid: Nueva época, 1995, pp.239-269.

DE MUNCK, J. "Les minorités en Europe", en LENOBLE, J. y DEWANDRE, N. (edts.) L'Europe au soir du siècle, Paris: Éditions Esprit, 1992, pp.137-161.

DE SOUSA SANTOS, Boaventura. "Una concepción multicultural de los derechos humanos". Revista Memoria. Bogotá, n. 101, 1997.

DE SOUSA SANTOS, Boaventura. La globalización del Derecho. Los nuevos caminos de regulación y la emancipación, Bogotá: Universidad Nacional de Colombia - ILSA, 1998.

DE SOUSA SANTOS, Boaventura. Crítica de la razón indolente: contra el desperdicio de la experiencia: para un nuevo sentido común: La ciencia, el derecho y la política en la transición paradigmática, Bilbao: Desclée de Bruower, 2003.
DE SOUSA SANTOS, Boaventura. Sociología jurídica crítica. Para un nuevo sentido común en el derecho, Trotta-ILSA, Madrid-Bogotá, 2009.

DUSSEL, Enrique. Hacia una filosofía política crítica, Bilbao: Desclée de Brouwer, 2001.

FERNÁNDEZ, Eusebio. "Derechos de la minorías culturales y de pensamiento" en SAUCA, José Mํa Derechos de las minorías y grupos diferenciados. Madrid: Escuela Libre Editorial, 1994, pp.297-213.

GARGARELLA, R., La sala de máquinas de la Constitución: Dos siglos de constitucionalismo en América Latina (1810-2010), Buenos Aires, Katz Editores, 2014.

GARGARELLA, R., "El nuevo constitucionalismo latino-americano", en Sinpermiso. Disponible en: http://www. sinpermiso.info/textos/el-nuevo-constitucionalismo-latinoamericano. (Acceso el 02.07.2016).

GARZÓN LÓPEZ, Pedro. "Pluralismo" en Eunomia. Revista en Cultura de la Legalidad, n5, septiembre 2013-febrero 2014 pp.186-193. Disponible en: http://eunomia.tirant. $\mathrm{com} / \mathrm{p}=2245$ (Acceso el 26-12-2014).

GARZÓN LÓPEZ, Pedro. Ciudadanía indígena. Del multiculturalismo a la colonialidad del poder. Prólogo de J.Mª . Sauca Cano. Madrid: Centro de Estudios Políticos y Constitucionales, 2001.

GOMES LEITE, Rodrigo. Will Kymlicka: Possibilidades e limites de uma abordagem multicultural da Sociedade Civil. 2007.

GORCZEVSKI, Clovis y BELLOSO MARTÍN, Nuria y. A necessária revisao do conceito de cidadania: movimentos sociais e novos protagonistas na esfera pública democrática, Porto Alegre: EDUNISC, 2011. Disponible em: ‘http:// www.unisc.br/portal/pt/editora/e-books.htmll.

HALL, Stuart. Da diáspora: identidades e mediaçōes culturais. Trad. de Adellaine La Guardia Resende y otros. Belo Horizonte: Editora da UFMG/Brasília: Representação da UNESCO no Brasil, 2003, p.51.

JUNQUEIRA, Carmen. Antropologia Indígena: uma introdução, história dos povos indígenas no Brasil. São Paulo: EDUC-Editora da PUC, 1991.

KMLICKA, Will. Ciudadanía Multicultural. Una teoría Iiberal de los derechos de las minorías. Trad. de Carmen Castells Auleda. Cubierta de Victor Viano. Barcelona: Ediciones Paidós Ibérica S.A., 1995.

PECES BARBA MARTÍNEZ, Gregorio. Curso de derechos humanos. Madrid: Eudema, 1995.

LAFER, Celso. A Reconstrução dos Direitos Humanos, São Paulo: Companhia das Letras, 1991. 
LEMOS DOS SANTOS FILHO, Roberto. "Índios, Convenção 169/OIT e Meio Ambiente". Revista CEJ (Brasília), v. 33, p. $16-21,2006$.

LIPOVETSKY, Giles. Los tiempos hipermodernos. Barcelona: Anagrama, 2006.

LOPES BARCENAS, Francisco. "Los sistemas indígenas de cargos en la Mixteca," en A. Hernández Nuñez y F. López Bárcenas (eds.), La fuerza de la costumbre: Sistema de cargos en la Mixteca oaxaqueña, México, Centro de Orientación y Asesoría a Pueblos Indígenas, 2002, p. 57 (Derechos Indígenas, vol. 8).

LUCAS, Javier de, "Para una discusión de la nota de universalidad de los derechos. (A propósito de la crítica del relativismo ético y cultural)", en Derechos y Libertades, n-3, Universidad Carlos III de Madrid-BOE, 1994, pp.259-312.

LUCAS, Javier. (de), El desafío de las fronteras. Derechos humanos y xenofobia frente a una sociedad plural. Madrid: Temas de Hoy, 1994.

LUCAS, Javier. (de), ¿Elogio de Babel? Sobre las dificultades del Derecho frente al proyecto intercultural. En:"ACFS" 31 (1994) p.21.

LUCAS, Javier. (de), Puertas que se cierran. Europa como fortaleza,Barcelona: Icaria, 1996.

BURITY, J. A. Globalização e identidade: desafios do multiculturalismo, Biblioteca virtual del Consejo Latinoamericano de Ciencias Sociales. Buenos Aires, 1999.

MCLAREN, Peter. Multiculturalismo crítico. Trad. Bebel Orofino Schaefer. São Paulo: Cortez, 1997.

MARÉS DE SOUZA FILHO, Carlos Frederico. Os Direitos Humanos e os povos indígenas. Disponible en: ‘http:// www.dhnet.org.br/direitos/sos/indios/mares.html)(Acceso el 26-12-2014).

MARÉS DE SOUZA FILHO, Carlos Frederico. Os Direitos Humanos e os povos indígenas. Disponible en: http:// www.dhnet.org.br/direitos/sos/indios/mares.html (Acceso el 26-12-2014). Sobre este tema el autor publicó un extenso artículo titulado "La universalidad parcial de los derechos humanos" en la serie documentos de ILSA, Bogotá. También está inserto en su libro: "O renascer dos povos indígenas para o direito", Curitiba: Juruá, 1998.

MCLAREN, Peter. Multiculturalismo crítico. Trad. Bebel Orofino Schaefer. São Paulo: Cortez, 1997.

MARTÍNEZ DE PISÓN, J., "Ciudadanía e inmigración". En: Ciudadanía. Dinámicas de pertenencia y exclusión. (Coordinadores: Mํ‥ Bernuz Beneítez y R. Susín Betrán). Servicio de Publicaciones de la Universidad de La Rioja, 2003.

MIGNOLO, Walter. La idea de América Latina. La herida colonial y la opción decolonial. Gedisa. Barcelona, España: 2007
NAVES, Márcio B.; DE AGUIAR BARROS, J. M.. (Orgs.) Crítica do Direito. São Paulo: Lech, 1980.

NEUENSCHWANDER MAGALHAES, Juliana. "Los límites del multiculturalismo en las sociedades multiculturales: formas de inclusión y exclusión" en Fórum. Historiae luris. Disponible en: < http://www.forhistiur.de/fr/2014-08-neuenschwander-magalhaes/> (Acceso el 02-04-2015).

NEUENSCHWANDER MAGALHAES. Juliana. "Los límites del multiculturalismo en las sociedades multiculturales: formas de inclusión y exclusión" en Fórum. Historiae luris. Disponible en: 〈http://www.forhistiur.de/fr/2014-08-neuenschwander-magalhaes/> (Acceso el 02-04-2015).

OLGIATI, Victoria., "El nuevo pluralismo jurídico y la lex mercatoria en la dinámica constitucional europea", en SILVA J.A. (coord.), Estudios sobre lex mercatoria. Una realidad internacional, UNAM, México D.F., 2006.

OLIVA MARTÍNEZ, Daniel J. "La deformación antropológica y su repercusión en el reconocimiento de los derechos humanos a los indígenas" en PECES-BARBA MARTíNEZ, Gregorio et at. (Editores) Historia de los Derechos Fundamentales (siglo XIX), Madrid: Dykinson, 2009, pp.575-576.

ORTIZ, R. Cultura Brasileira e Identidade Nacional. São Paulo: Brasiliense, 2006.

PÉREZ LUÑ̃, A. E. La polémica sobre el Nuevo Mundo. Los clásicos españoles de la Filosofía del Derecho, Madrid: Trotta, 1992.

PÉREZ LUÑO, Antonio-Enrique. Trayectorias contemporáneas de la Filosofía y la teoría del Derecho. Sevilla: Grupo Nacional de Editores, 2003.

PETER M. BLAU, "II paradosso del multiculturalismo" en Rassegna Italiana di Sociologia, Bologna: II Mulino, nำ1,1995, pp. 53-63.

Quijano, Aníbal. "Colonialidad del poder, eurocentrismo y América Latina". En: Edgardo Lander (comp.), Colonialidad del saber: eurocentrismo y ciencias sociales. Perspectivas latinoamericanas, Buenos Aires, Clacso/Unesco, pp. 201246: 2000.

PORTELA, Fernando y MINDLIN, Betty. A questão do índio. São Paulo: Ática, 1991.

RAWLS, John. El liberalismo político. Barcelona: Grijalvo Mondadori, 1997.

ROULAND, Norbert. Direito das minorías e dos povos autóctones. Brasília: Editora UnB, 2004.

SÁNCHEZ RUBIO, David. "Sobre el derecho alternativo. Absolutización del formalismo, despotismo de la ley y legitimidad", en DE LA TORRE RANGEL, J.A. (ed.), Derecho alternativo y crítica jurídica, México, D.F.: Porrúa, 2002. 
SANTOS, M. Por uma outra globalização: do pensamento único à consciência universal. 9a․ ed. Rio de Janeiro: Record, 2002.

SARTORI, Giovanni Pluralismo, multiculturalismo e stranei. Trad. de M.A. Ruíz de Azúa. La sociedad multiétnica. Pluralismo, multiculturalismo y extranjeros. Madrid: Taurus, 2001.

SEMPRINI, A. Multiculturalismo. Bauru: EDUSC, 1999.

SIEDER, R. Multiculturalism in Latin America: Indigenous rights, diversity and democracy. Inglaterra: Palgrave/ILAS, 2002.

SIEDER, R., "Pueblos indígenas y derecho(s) en América Latina" en Rodríguez Garavito, C. (Coordinador) El Derecho en América Latina. Un mapa para el pensamiento jurídico del siglo XXI, Buenos Aires, Siglo XXI Editores, 2011, pp.303322. Disponible en: «ttp://www.justiciaglobal.net/files/actividades/fi_name_recurso.8.pdf. (Acceso el 05.06.2016).

SILVA, Larissa Tenfen. "O multiculturalismo e a política de reconhecimento de Charles Taylor" en Novos Estudos Jurídicos, v.11, Universidade do Vale do Itajaí/SC: Brasil, n.2, jul/dez.06, p. 313/322.

SORIANO, Ramón. Los derechos de las minorías. Sevilla, Editorial MAD, 1999.

SOUZA, M.L, El uso alternativo del Derecho. Génesis y evolución en Italia, España y Brasil, Universidad Nacional de Colombia-ILSA: Bogotá, 2001.

STAVENHAGEN, Rodolfo. Clases, colonialismo y aculturación, Guatemala, Ministerio de Educación, 1968.

STAVENHAGEN, Rodolfo. Los pueblos indígenas y sus derechos: Informes temáticos del relator especial sobre la situación de los Derechos Humanos y las libertades fundamentales de los pueblos indígenas del Consejo de Derechos Humanos de la Organización de las Naciones Unidas (2002-2007).

TAYLOR, Charles. Multiculturalismo. La política del reconocimiento. México: Fondo de Cultura Económica, 2010.

TORBISCO CASALS, Neus, Derechos indígenas: reconocimiento y desafíos para la democracia constitucional y para los derechos humanos" en HIERRO, Liborio L (Coord.) Autonomía individual frente a autonomía colectiva. Derechos en conflicto. Madrid: Marcial Pons, 2014, pp.116-117.

TOURAINE, Alain. "¿Después del posmodernismo?... La modernidad" en RODRIGUEZ MAGDA, R.M. y ÁFRICA VIDAL, M.C. (edts.) Y después del posmodernismo ¿quué?, Barcelona: Anthropos, 1988.

VIVEIROS DE CASTRO, Eduardo. Rio de Janeiro: Beco do Azougue, 2008.

WOLKMER, Antonio Carlos. Pluralismo Jurídico. Fundamentos para una nueva cultura jurídica, Mad, Sevilla, 2000.
WOLKMER, Antonio Carlos. "El humanismo en la tradición de la cultura jurídica Latino-Americana". Disponible en la World Wide Web: ‘http://bibliotecavirtual.clacso.org. ar/ar/libros/derecho/wolk1.rtf s. (Acceso el 26-12-2014).

WOLKMER, Antonio Carlos. (Org.). Direito e justiça na América Indígena: da conquista à colonização. Porto Alegre: Livraria do Advogado, 1998; História do direito no Brasil. 3ㅁ․ ed. Rio de Janeiro, Forense, 2002.

Wolkmer: WOLKMER, Antonio Carlos y CORREAS, Oscar. Crítica Jurídica na América Latina. Augascalientes/Florianópolis, UFRSC-Mispat, 2013.

WOLKMER, Antonio Carlos. "Pluralismo juridico, movimentos sociais e processos de lutas desde America Latina" en WOLKMER,A. C.; FERNANDEZ M. LIXA, I. (Orgs.) Constitucionalismo, Descolonización y pluralismo jurídico en América Latina, NEPE - Universidad Federal de Santa Catarina (UFSC) Aguascalientes / Florianópolis, 2015, pp. 95-103.

YOUNG, Iris Marion. Justice and the Politics of Difference. New Jersey, Princenton: Princenton University Press, 1990.

YRIGOYEN FAJARDO, Raquel. Pautas de coordinación entre el derecho indígena y el derecho estatal, Fundación Myrna Mack, Guatemala, 1999; CLAVERO, Bartolomé. Derecho Indígena y Derecho Constitucional en América, Siglo XXI, México, D.F., 1994.

YRIGOYEN FAJARDO, R.Z., "El horizonte del constitucionalismo pluralista: del multiculturalismo a la descolonización" en Rodríguez Garavito, C. (Coordinador) El Derecho en América Latina. Un mapa para el pensamiento jurídico del siglo XXI, Buenos Aires, Siglo XXI Editores, 2011, pp. 139-160. Disponible en: ‘ http://www.justiciaglobal.net/files/actividades/fi_name_recurso.8.pdf.. (Acceso el 05.06.2016).

WOLFGANG SARLET, Ingo. A Eficácia dos Direitos Fundamentais. $2^{\underline{a}}$ ed. Porto Alegre: Livraria do Advogado, 2001.

ZAPATA-BARRERO, R. "La ciudadanía en contextos de multiculturalidad: processos de câmbios de paradigmas", Anales de la Cátedra Francisco Suárez, no37, 2003, pp.173-199.

\section{Documentos}

Declaración de la Asamblea General de Naciones Unidas sobre los Derechos de los pueblos indígenas. Disponible en:http://www.un.org/esa/socdev/unpfii/documents/ DRIPS_es.pdf; (Acceso el 28.02.2015).

Directrices sobre los asuntos de los Pueblos indígenas. Grupo de las Naciones Unidas para el Desarrollo, 2008. Disponible en «http://www2.ohchr.org/english/issues/indigenous/docs/UNDG-Directrices_pueblos_indigenas.pdf. (Acceso el 10.12.2015). 
Recomendación General No. 23: La situación de las poblaciones indígenas del Comité para la Eliminación de la Discriminación Racial subraya esta situación y propone varias medidas para su mejoramiento. Disponible en: http://www.unhchr.ch/tbs/doc.nsf/(Symbol)/2a12ea8905164c6e8025684a00545d05?Opendocument.

Recomendación General No. 21: Derecho a la libre determinación del Comité para la Eliminación de la Discriminación Racial hace referencia especial a la autodeterminación de los pueblos indígenas. Disponible en: http://www.unhchr.ch/tbs/doc.nsf/(Symbol)/ b352135254eb2c468025652b005a4a64?Opendocument.

\section{Jurisprudencia}

Informe de Admisibilidad No. 125/10, Petición 250/04 Pueblos Indígenas de Raposa Serra do Sol (Brasil), 23 de octubre de 2010.Disponible en: http://www.oas.org/es/cidh/ indigenas/decisiones/cidh.asp (Acceso el 30-12-2014).

Resolución aprobada por la Asamblea General [sin remisión previa a una Comisión Principal (A/61/L67 y Add.1)] por la que se aprueba la Declaración de las Naciones Unidas sobre los derechos de los pueblos indígenas, el 3 de septiembre de 2007, Anexo, p.2. Disponible en: < http://www.un.org/esa/socdev/unpfii/documents/DRIPS_es.pdf. (Acceso el 30-12-2014).

\section{Saulo Tarso Rodrigues}

Pós-Doutor em Direito Constitucional - Uppsala University - Sweden, Doutor com “Distinção e Louvor" em Sociologia do Estado e do Direito na disciplina de Direitos Humanos pela Universidade de Coimbra, sob orientação do Prof. Dr. Boaventura de Sousa Santos, Mestre em Direito do Estado pela Unisinos-RS e Graduado em Direito pela Unijuí - RS. Pesquisador Colaborador do Núcleo "Direito, Democracia e Sociedade" do Centro de Estudos Sociais da Universidade de Coimbra, Pesquisador Colaborador do Programa de Doutoramento Human Rights In Contemporary Societes na Unidade Curricular "History of Human Rights an North-South Divide" do Cescoimbra, Professor Adjunto I da Universidade Federal do Mato Grosso, membro do Grupo de Pesquisa Movimentos Sociais e Educação (GPMSE) UFMT, pesquisador no grupo de pesquisa TEDEPES - Teoria do Direito, Educação Popular e Economia Solidária, da Universidade do Estado de Mato Grosso, pesquisador no grupo de pesquisa Direitos dos Conhecimentos, da Universidade Federal do Amazonas e do Grupo de Pesquisa A Efetivação dos Direitos Humanos da Universidade Federal de Rio Grande. Diretor do Núcleo de Pesquisa Minga-Constitucionalismo Latino Americano, Novas Intersubjetividades e Emancipação Social, da Universidade Federal do Mato Grosso, Membro Coordenador do Grupo de Pesquisa registrado no Diretório Central de Grupos do CNPQ, Constitucionalismo Latino Americano, Novas Intersubjetividades e Emancipação Social, Professor efetivo do Programa de Mestrado em Direito Ambiental da UFMT. Tem experiência na área de Direito, com ênfase Filosofia do Direito. Área de atuação: Teoria do Estado, Teoria do Direito, Teoria Constitucional, Democracia radical e póscolonialismo: as perspectivas para a reconstrucão da cidadania multicultural e intercultural. Direito e pós-colonialidade.

\section{Núria Belloso Martín}

Catedrática Acreditada de Filosofía del Derecho. Doctora en Derecho por la Universidad de Valladolid. Actualmente es Profesora Titular de Filosofía del Derecho en la Universidad de Burgos. Directora del Departamento de Derecho Público. Coordinadora del Máster en Derecho de la Empresa y de los Negocios. Coordinadora del Programa de Doctorado en Derecho Público "Sociedad plural y nuevos retos del Derecho" desde 1995. Mediadora Civil y Mercantil. Desde el curso académico 2002-2003 dirige el Curso de Postgrado Universitario de "Especialista en Mediación Familiar" en la Universidad de Burgos. Es también Directora del Curso de Especialista en Mediación Civil y Mercantil. Autora de más de seis decenas de artículos científicos publicados en Revistas y obras colectivas nacionales e internacionales, además de una docena de monografías. Es responsable académica del Programa de Intercambio de alumnos y profesores con Universidades italianas en el ámbito del Programa Europeo Sócrates. Ha sido Profesora en diversas Universidades de Latinoamérica y Centroamérica (Brasil, México, Argentina, etc.), impartiendo cursos de Maestría y de Doctorado, y dirigiendo diversos trabajos de investigación. Participa en diversos Proyectos de investigación financiados por el CNpQ (Brasil). Ha dirigido varios Proyectos de investigación en el marco del Programa de la Agencia Española de Cooperación Iberoamericana -PCl-. Es Directora de Relaciones Internacionales y Cooperación del Núcleo de Pesquisa "Minga. Constitucionalismo democrático latinoamericano, novas intersubjetividades e emancipação social" (UFMT-Brasil). Sus principales líneas de investigación son la Escuela Española del siglo XVI, ciudadanía, democracia y participación política, formas complementarias de resolución de conflictos y Teoría de la justicia y activismo judicial. 